\title{
Model-data comparison and data assimilation of mid-Holocene Arctic sea ice concentration
}

\author{
F. Klein ${ }^{1}$, H. Goosse ${ }^{1}$, A. Mairesse ${ }^{1}$, and A. de Vernal ${ }^{2}$ \\ ${ }^{1}$ Université catholique de Louvain, Earth and Life Institute, Georges Lemaître Centre for Earth and Climate Research, \\ Place Louis Pasteur, 3, 1348 Louvain-la-Neuve, Belgium \\ ${ }^{2}$ GEOTOP, Université du Québec à Montréal, P.O. Box 8888, succursale “centre ville”, Montréal, QC H3C 3P8, Canada
}

Correspondence to: F. Klein (francois.klein@uclouvain.be)

Received: 15 November 2013 - Published in Clim. Past Discuss.: 10 December 2013

Revised: 3 April 2014 - Accepted: 15 April 2014 - Published: 16 June 2014

\begin{abstract}
The consistency between new quantitative reconstructions of Arctic sea ice concentration based on dinocyst assemblages and the results of climate models has been investigated for the mid-Holocene. The response of the models mainly follows the increase in summer insolation, modulated to a limited extent by changes in atmospheric circulation. This leads to differences between regions in the models that are smaller than in the reconstruction. It is, however, impossible to precisely assess the models' skills because the sea ice concentration changes at the mid-Holocene are small in both the reconstructions and the models and of the same order of magnitude as the reconstruction uncertainty. Performing simulations with data assimilation using the model LOVECLIM amplifies the regional differences and improves the modeldata agreement as expected. This is mainly achieved through a reduction of the southward winds in the Barents Sea and an increase in the westerly winds in the Canadian Basin, inducing an increase in the ice concentration in the Barents and Chukchi seas. This underlines the potential role of atmospheric circulation in explaining the reconstructed changes during the Holocene.
\end{abstract}

\section{Introduction}

Sea ice is a key element of the global climate system. First, it enhances climate response at high latitudes of the Northern Hemisphere as it is involved in various feedbacks, in particular the classic ice albedo feedback (Holland and Bitz, 2003; Serreze et al., 2009; Screen and Simmonds, 2010; Stroeve et al., 2011). Second, sea ice plays a role in deep-water formation through brine rejection which is a crucial driver of the global thermohaline circulation (Lohmann and Gerdes, 1998; Goosse and Fichefet, 1999). Third, it modifies the exchanges of heat and gases between the atmosphere and polar oceans because of its insulation properties (Ebert and Curry, 1993). Consequently, changes in Arctic sea ice cover and thickness influence the atmospheric and hydrographic conditions at high latitudes, which may in turn have an impact on the European and the North American climate (e.g. Serreze et al., 2007; Francis and Vavrus, 2012).

The processes involved in sea ice behaviour are complex, which explains why climate models still have clear biases in simulating sea ice for present-day conditions (Stroeve et al., 2012; Massonnet et al., 2012). It is thus important to improve our understanding of sea ice and its representation in climate models, especially in the current context of a decreased Arctic sea ice cover and thickness over the past few decades (Serreze et al., 2007; Stroeve et al., 2011), likely related to anthropogenic climate change (e.g. Notz and Marotzke, 2012).

The analysis of past sea ice fluctuations provides an interesting complement to the study of the last decades, in particular the ones focusing on the Holocene (the current interglacial) as the boundary conditions of the climate system were roughly similar to the present ones (Wanner et al., 2008). In the absence of direct instrumental measures, this can be achieved by two complementary approaches, proxybased reconstructions (e.g. Funder et al., 2011; Müller et al., 2012) and modelling (e.g. Goosse et al., 2013; Berger et al., 2013). This allows us, amongst other things, to contextualize the recent climate changes, to validate climate models results and to improve the physical understanding of the system (Zhang et al., 2010; Braconnot et al., 2012). 
Here we will focus on the mid-Holocene (6 ka, hereafter $\mathrm{MH})$ as it is a classic period that is reasonably well documented as much in terms of proxy data (see Sect. 3.1) as in terms of model results since it is a standard target for the Paleoclimate Model Intercomparison Project (PMIP; e.g. Braconnot et al., 2007). The MH coincides with the end of a warm period in the Arctic that started about $9 \mathrm{ka}$ (Sundqvist et al., 2010) due to a high orbitally driven summer insolation. Insolation had its maximum at around $11 \mathrm{ka}$ (Berger, 1978) but the warmest conditions have been asynchronous across the Arctic due to the effect of the lingering Laurentide Ice Sheet (Kaufman et al., 2004; Renssen et al., 2009). At 6 ka, some regions were thus already experiencing a cooling (for instance, Alaska) while others were still close to their maximum temperature (like northeast Canada) (Kaufman et al., 2004).

Although most Arctic proxies support lower sea ice conditions during the $\mathrm{MH}$ as compared to the entire Holocene, the recorded changes are not homogeneous between the different regions (see Sect. 3.1). In addition to modifications in the oceanic and atmospheric circulations or to the influence of the remnant Laurentide Ice Sheet that could have an impact on a large scale, complex local topography can be responsible for a high heterogeneous response on small spatial scales. This is particularly the case in the Canadian Arctic Archipelago (CAA) with its complicated disposition of narrow straits, where proxy records display contrasted signals for nearby locations (e.g. Vare et al., 2009; Atkinson, 2009). Furthermore, the uncertainties related to the interpretation of proxies or to their dating can also explain some of the discrepancies (Polyak et al., 2010; Sundqvist et al., 2010).

In qualitative agreement with data, models simulate less sea ice extent in summer during the $\mathrm{MH}$ as compared to the pre-industrial (hereafter PI) conditions, following the higher summer insolation (Berger et al., 2013; Goosse et al., 2013). However, no quantitative estimate of the agreement exists up to now, given the lack of a consistent quantitative sea ice reconstruction covering the Arctic. In this context, this paper aims at comparing the $\mathrm{MH}$ sea ice concentration simulated by the model of intermediate complexity LOVECLIM and by general circulation models (GCMs) with new quantitative reconstructions of Arctic sea ice concentration based on dinocyst assemblages (de Vernal et al., 2013a). This modeldata comparison is intended first to estimate whether climate models are able to reproduce the spatial pattern deduced from proxy records. In a second step, a simulation with data assimilation is performed with the climate model LOVECLIM. The data assimilation method is constructed in such a way that the impact of this additional constraint improves the consistency between the model results and the reconstruction. This allows us to investigate in more details the processes governing sea ice conditions at $6 \mathrm{ka}$ and analysing the potential origin of the biases seen in the simulations without data assimilation.
The models selected, the experimental design and the proxy reconstructions based on dinocyst assemblages are presented in Sect. 2. Section 3 starts with a short description of the observed sea ice changes. It is followed by an analysis of the results of the simulations without data assimilation and finally of the simulation with data assimilation. Conclusions are presented in Sect. 4.

\section{Methodology}

\subsection{Model description}

Experiments have been performed with the threedimensional earth climate model of intermediate complexity LOVECLIM version 1.2 (Goosse et al., 2010). It includes a representation of the atmosphere, ocean, sea ice and land surface including vegetation. The atmospheric component is ECBilt2 (Opsteegh et al., 1998), a quasi-geostrophic spectral model with T21 horizontal resolution (corresponding to $5.6^{\circ} \times 5.6^{\circ}$ latitude-longitude) and three vertical levels in addition to the surface. Ocean and sea ice are simulated by CLIO3 (Goosse and Fichefet, 1999), which is a general circulation model coupled to a comprehensive thermodynamic-dynamic sea ice model. Its horizontal resolution is $3^{\circ} \times 3^{\circ}$ and the ocean is divided into 20 unevenly spaced vertical levels. LOVECLIM also contains the vegetation model VECODE (Brovkin et al., 2002) that takes into account the distribution of three different land covers (deserts, grasses and forests) using the same resolution as ECBilt2. Due to its coarse resolution and to simplifications introduced in the representation of some atmospheric processes, LOVECLIM is much faster than the more sophisticated coupled climate models. It allows us to produce the large amount of simulations required for the data assimilation process (see Sect. 2.2). In this study, two different $6 \mathrm{ka}$ LOVECLIM simulations are examined: LOVECLIM without assimilation (referred as LOVECLIM no assim) and LOVECLIM with sea ice data assimilation (LOVECLIM assim SIC).

In addition to LOVECLIM simulations, MH experiments performed with GCMs in the framework of the third phase of the PMIP3 (Otto-Bliesner et al., 2009), referred to as midHolocene, are analysed. The simulations from which the PI reference values have been obtained cover the period 18502000 and are referred as historical in the fifth phase of the Coupled Model Intercomparison Project; (CMIP5, Taylor et al., 2012). The GCMs selected here (Table 1) are the ones for which the variables of interest for our diagnostics were available at the time of the analysis.

\subsection{Data assimilation method}

LOVECLIM results have been constrained to follow a proxybased sea ice reconstruction through a process of assimilation, using a particle filter with resampling (van Leeuwen, 
Table 1. CMIP5/PMIP3 GCMs characteristics and references.

\begin{tabular}{|c|c|c|c|}
\hline Model name & Modelling centre & $\begin{array}{l}\text { Number of } \\
\text { members for } \\
\text { historical } \\
\text { simulations }\end{array}$ & Reference \\
\hline BCC-CSM1-1 & $\begin{array}{l}\text { Beijing Climate Center, } \\
\text { China Meteorological Administration }\end{array}$ & 3 & Wu et al. (2014) \\
\hline CCSM4 & National Center for Atmospheric Research & 6 & Gent et al. (2011) \\
\hline CNRM-CM5 & $\begin{array}{l}\text { Centre National de Recherches Meteorologiques/ } \\
\text { Centre Europeen de Recherche et Formation } \\
\text { Avancees en Calcul Scientifique }\end{array}$ & 10 & Voldoire et al. (2012) \\
\hline CSIRO-Mk3.6.0 & $\begin{array}{l}\text { Commonwealth Scientific and Industrial Research } \\
\text { Organization in collaboration with Queensland } \\
\text { Climate Change Centre of Excellence }\end{array}$ & 10 & Rotstayn et al. (2009) \\
\hline HadGEM2-CC & Met Office Hadley Centre & 3 & Collins et al. (2011) \\
\hline HadGEM2-ES & Met Office Hadley Centre & 4 & Collins et al. (2011) \\
\hline MIROC-ESM & $\begin{array}{l}\text { Japan Agency for Marine-Earth Science and } \\
\text { Technology, Atmosphere and Ocean Research } \\
\text { Institute (The University of Tokyo), and } \\
\text { and National Institute for Environmental }\end{array}$ & 3 & Watanabe et al. (2011) \\
\hline MPI-ESM-P & Max Planck Institute for Meteorology & 2 & Stevens et al. (2013) \\
\hline MRI-CGCM3 & Meteorological Research Institute & 5 & Yukimoto et al. (2012) \\
\hline
\end{tabular}

2009; Dubinkina et al., 2011), in a similar manner as in several recent studies (e.g. Goosse et al., 2012; Mathiot et al., 2013; Mairesse et al., 2013). First, an ensemble of 96 simulations (called particles) is initialized from a slightly different sea surface temperature for each particle, allowing different time developments. After one year of simulation, the likelihood of each particle is computed from the difference between the proxy-based reconstructed and the simulated sea ice concentration anomalies (6 ka minus PI results), taking into account the errors. Depending on their likelihood, i.e. their ability to reproduce the signal derived from the available reconstructions, the particles are then either abandoned if their likelihood is low or kept as a basis for the next year's simulation if their likelihood is high enough. In order to maintain a constant number of particles until the end of the simulated period, a resampling, depending on the particles likelihood, is conducted annually: the particles with a higher likelihood are copied more times than the others. Finally, the initial conditions of each particle are once more perturbed by adding a small noise to the sea surface temperature of the copies in order to obtain different time developments for the following year, and the whole procedure is repeated sequentially every year until the end of the simulation, here after 400 years.

\subsection{Proxy-based sea ice reconstruction}

The MH proxy-based sea ice reconstructions used to evaluate model performance and to constrain LOVECLIM simulations is derived from cysts produced by dinoflagellates (dinocysts). The dinocyst distribution in Arctic and subarctic seas is indeed controlled by several environmental parameters including productivity, salinity, temperature and, most importantly, sea ice (de Vernal and Rochon, 2011). The data set is based on the dinocyst content of 18 cores collected in the North Atlantic and Arctic oceans (Table 2 and Fig. 1). Sea ice is expressed in terms of annual mean concentration (in \%) and is associated with a standard error of $\pm 11 \%$ (de Vernal et al., 2013a). This value is used as the estimate of the reconstruction uncertainty for the evaluation of the likelihood in the experiment with data assimilation.

The sea ice reconstructions have inherent uncertainties that are linked on the one hand to the intrinsic variability of sea ice and accuracy of observations and, on the other hand, to limitation related to the proxy and its application (see the discussion in de Vernal et al., 2013b). Whereas interannual variations of sea ice cover as measured instrumentally over the last decades account for a standard deviation close to $10 \%$ on average, the largest source of uncertainties is probably the mismatch between the time interval of instrumental data used as reference (here, 1953-2003) and the time interval represented by dinocyst populations in surface sediment samples, which may cover centuries. Such limitations apply to all sedimentary proxies. In the case of dinocyst data, which include 66 taxa and 1492 reference data points from the Northern Hemisphere, about half of them being representative of seasonal sea ice environment, the application of the modern analogue technique (MAT) permits quantitative reconstruction with an accuracy of $\pm 11 \%$. Regardless of the sources of uncertainties inherent to both the reference and proxy data sets, 
Table 2. Description of all the cores available at $6 \pm 0.5 \mathrm{ka}(\mathrm{AD}-4050 \pm 0.5 \mathrm{kyr})$ used to reconstruct sea ice cover (de Vernal et al., $2013 \mathrm{a})$. The table shows the core ids used in this study, their name, location, latitude, longitude and the reconstructed sea ice concentration (sic ano) anomalies (reference period AD 1850-1900).

\begin{tabular}{lllllr}
\hline Id & Core name & Location & Lat & Long & 6k sic ano (\%) \\
\hline 1. & HLY05JPC & Chukchi Sea & 72.69 & -157.52 & 8.95 \\
2. & GGC19 & Chukchi Sea & 72.16 & -155.51 & 22.60 \\
3. & LS009 & Lancaster Sound & 74.19 & -81.195 & -4.49 \\
4. & BS004 & Barrow Strait & 74.27 & -91.09 & 12.60 \\
5. & HU008 & Nares Strait & 77.27 & -74.32 & -14.53 \\
6. & HU021TWC & Labrador Sea & 58.37 & -57.51 & -5.82 \\
7. & HU013 & Labrador Sea & 58.21 & -48.31 & -12.59 \\
8. & MD2227 & Atlantic & 58.21 & -48.37 & -5.08 \\
9. & HU044 & East Canadian margin & 44.49 & -55.19 & 0.14 \\
10. & MD2033 & Gulf of St Lawrence & 44.66 & -55.62 & -0.52 \\
11. & HU094 & Atlantic & 50.2 & -45.69 & -8.25 \\
12. & HU085 & Atlantic & 53.98 & -38.64 & -1.85 \\
13. & MD2254 & Atlantic & 56.8 & -30.66 & 3.53 \\
14. & HM025 & Faroe-Shetland Channel & 60.11 & -6.07 & 1.61 \\
15. & JM1207 & Denmark Strait & 68.1 & -29.35 & 0.88 \\
16. & M23323 & Norwegian Sea & 67.77 & 5.92 & 2.07 \\
17. & MSM712 & Fram Strait & 78.92 & 6.77 & -5.45 \\
18. & PL112 & Barents Sea & 71.27 & 42.61 & 5.75 \\
\hline
\end{tabular}

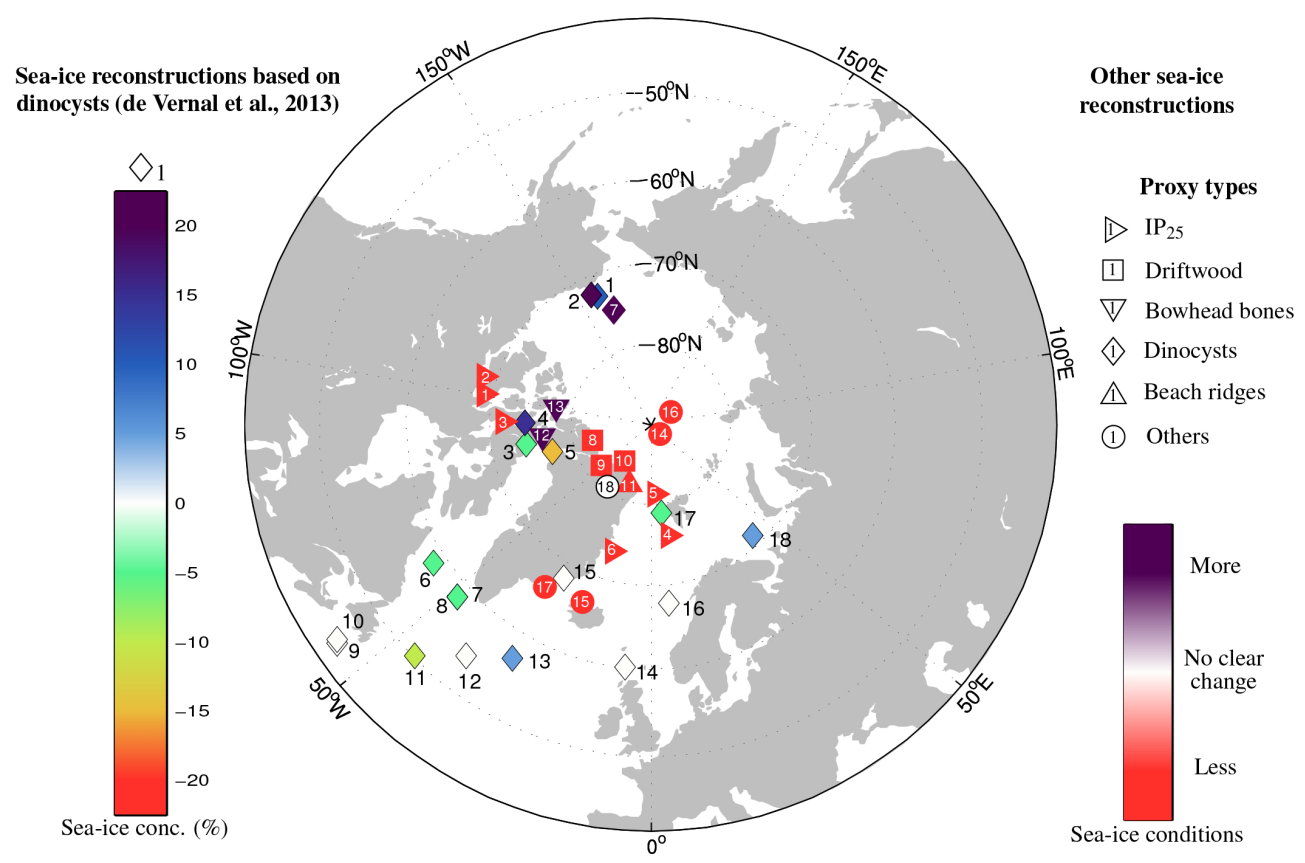

Figure 1. Reconstructions of sea ice conditions for the mid-Holocene. Diamonds markers with number next to them (refer to the lefthand coloured bar) correspond to MH sea ice concentration anomalies (in \%) using the reference period AD 1850-1900 based on dinocyst assemblages (de Vernal et al., 2013a). The other markers with numbers inside are the MH sea ice signals derived from different sea ice proxies (see key on the right). Sea ice conditions are expressed in terms of more (blue) or less (red) sea ice in the MH as compared to a reference period which varies depending on the record but which generally covers most of the Holocene (see Table 3 ). The location of some proxies has been shifted slightly for an improved readability.

the accuracy is calculated from the residuals or difference between observed and estimated values and corresponds to the standard deviation of the residuals. In addition to the ac- curacy, uncertainties in reconstruction of past sea ice conditions may come from poor analogue situations or low counts making the statistics for reconstructions weaker. This is why 
Table 3. Arctic sea ice reconstructions displayed in Fig. 1 and their signal in the $\mathrm{MH}$ as compared to the reconstruction means.

\begin{tabular}{|c|c|c|c|c|c|}
\hline Id. & Proxy type & Reconstructed variable & Result at $6 \mathrm{ka}$ & Compared to & Reference \\
\hline 1 & $\mathrm{IP}_{25}$ & Spring sea ice occurrence & Low & $7 \mathrm{ka}$-present & Belt et al. (2010) \\
\hline 2 & $\mathrm{IP}_{25}$ & Spring sea ice occurrence & Low & $7 \mathrm{ka}$-present & Belt et al. (2010) \\
\hline 3 & $\mathrm{IP}_{25}$ & Spring sea ice occurrence & Low & $10-0.4 \mathrm{ka}$ & Vare et al. (2009) \\
\hline 4 & $\mathrm{IP}_{25}, \mathrm{PIP}_{25}, \mathrm{IRD}$ & Sea ice occurrence & Low & PI period & Müller et al. (2012) \\
\hline 5 & $\mathrm{IP}_{25}$ & Sea ice cover & Low & PI period & Müller et al. (2012) \\
\hline 6 & $\mathrm{IP}_{25}$, brassicasterol & Sea ice cover & Low & PI period & Müller et al. (2012) \\
\hline 7 & Dinocyst & Sea ice duration & Increased & $8 \mathrm{ka}$-present & Farmer et al. (2011) \\
\hline 8 & Driftwood & Sea ice conditions & More open water & $10 \mathrm{ka}$-present & England et al. (2008) \\
\hline 9 & Driftwood & Summer sea ice conditions & More open water & $11 \mathrm{ka}$-present & Bennike (2004) \\
\hline 10 & Driftwood, beach ridges & Sea ice conditions & Long open-water periods & $10 \mathrm{ka}$-present & Funder et al. (2011) \\
\hline 11 & Beach ridges & Sea ice conditions & No multiyear sea ice & - & Möller et al. (2010) \\
\hline 12 & Bowhead & Summer sea ice conditions & Severe & $10.5 \mathrm{ka}-$ present & Dyke et al. (1996) \\
\hline 13 & Bowhead & Summer sea ice conditions & Severe & $10.5 \mathrm{ka}-$ present & Atkinson (2009) \\
\hline 14 & Foraminifera & Sea ice cover & Low & $14-2 \mathrm{ka}$ & Hanslik et al. (2010) \\
\hline 15 & Quartz & Drift ice cover & Minimal & $11.7 \mathrm{ka}$-present & Andrews et al. (2009) \\
\hline 16 & Ostracode & Sea ice cover & Low & Holocene & Cronin et al. (2010) \\
\hline 17 & IRD & Sea ice condition & Low & $10 \mathrm{ka}$-present & Jennings et al. (2002) \\
\hline 18 & $\delta_{13} \mathrm{C}, \mathrm{TOC}$ & Sea ice condition & Mean & $11 \mathrm{ka}$-present & Olsen et al. (2012) \\
\hline
\end{tabular}

indices of reliability have been proposed in order to assess the quality of reconstructions. In the present case, more than $95 \%$ of reconstructions are labelled with high-quality indices (cf. de Vernal et al., 2013a, and data posted on the Geotop website).

The proxy records include variability on a (multi-)centennial timescale that could not be reproduced in the time slice experiments performed following the PMIP protocol. Therefore, we consider the MH as a period of $1 \mathrm{kyr}$, i.e. $6 \pm 0.5 \mathrm{ka}$, which limits the contribution of internal variability and non-orbital forcings. The choice of such an interval length also allows us to neglect the potential biases related to dating uncertainties.

The model-data comparison and the data assimilation are performed using anomalies and considering the PI conditions (AD 1850-1900) as a reference period. We have preferred this option rather than using recent observed sea ice cover, since comparing sea ice conditions inferred from dinocyst content with satellite data would have led to additional uncertainties. Furthermore, the recent period is far from being adequate for calculating anomalies since it presents rapid changes characterized by a significant decrease in sea ice (e.g. Stroeve et al., 2011). Unfortunately, many of the available reconstructed time series used here are not continuous up to AD 1900. We have thus decided to reconstruct the reference data set by computing a linear interpolation of those time series up to the period AD 1850-1900. To avoid extrapolating over too long periods, the proxy records ending before $2 \mathrm{ka}$ have been discarded from our analysis.

\subsection{Experimental design}

All the MH simulations represent equilibrium conditions corresponding to $6 \mathrm{ka}$. They use the orbital forcing, following Berger (1978). The changes in greenhouse gas concentration are taken from Flückiger et al. (2002) for LOVECLIM simulations, which are slightly different from the ones used in the framework of the CMIP5/PMIP3 (http://pmip3.lsce.ipsl.fr/). As in Mathiot et al. (2013) and Mairesse et al. (2013), LOVECLIM simulations also consider slight changes in ice sheet topography and surface albedo, following the reconstruction of Peltier (2004), as well as in freshwater fluxes from Antarctic ice sheet melting according to the results of Pollard and DeConto (2009). This represents a small difference as compared to the CMIP5/PMIP3 protocol, as the latter prescribes present-day ice sheet topography and no change in freshwater fluxes at $6 \mathrm{ka}$ with respect to the present. However, this has virtually no effect on results.

For the reference period corresponding to the PI values, we have averaged all the results from available members for each GCM (Table 1) and from a set of experiments with LOVECLIM (Crespin et al., 2012) over the period AD 1850-1900 (over the period AD 1860-1900 in the cases of HadGEM2CC and HadGEM2-ES).

\section{Results and discussion}

\subsection{Sea ice changes at $6 \mathrm{ka}$ deduced from observations}

Despite the general context of high summer temperatures characterizing the high northern latitudes during the early to mid-Holocene (Wanner et al., 2008; Sundqvist et al., 2010), 
the quantitative proxy-based sea ice reconstructions based on dinocysts display heterogeneous and weak anomalies at $6 \mathrm{ka}$ (Fig. 1). Lower annual mean sea ice concentration is recorded in the MH in the Fram Strait, northern Baffin Bay and Labrador Sea as compared to the PI period. By contrast, the $\mathrm{MH}$ is characterized by higher sea ice concentration in the Chukchi Sea, and to a lesser extent, in the Barents Sea and in the Barrow Strait (in the CAA; Fig. 1).

Overall, this data set appears consistent with other sea ice proxy-based reconstructions, even if the consistency can only be examined qualitatively since most of the available proxy-based sea ice reconstructions are qualitative or semiquantitative. Furthermore, most of the mid-Holocene conditions depicted by those records are here compared to the whole (or most) of the Holocene and not to the PI period as displayed in our analysis, since data are often not valuable for the recent period. Information about these proxy records and their signal at $6 \mathrm{ka}$ can be found in Table 3 and Fig. 1 .

In the CAA, the MH sea ice record deduced from various proxies is very heterogeneous, which is consistent with the dinocyst-based records (id 3-5). On the one hand, the little amount of bowhead bones found indicates high sea ice coverage (Dyke et al., 1996; Atkinson, 2009), but, on the other hand, the analysis of $\mathrm{IP}_{25}$ in several sediment cores suggests low spring sea ice occurrence in the MH compared to the whole Holocene period (Vare et al., 2009; Belt et al., 2010). This heterogeneity can, at least partly, be due to the numerous narrow straits being associated with different circulation patterns (e.g. Lietaer et al., 2008).

Further west, the higher sea ice concentration recorded over the Chukchi Sea in the MH (id 1 and 2) is in agreement with relatively low bottom-water temperature on the shelf as recorded from oxygen isotopes in benthic foraminifers (Farmer et al., 2011) as well as with the relatively low temperature shown by several proxies in Alaska (Kaufman et al., 2004).

The sea ice records show a relatively clear picture in the north of Greenland, Svalbard, the east of Greenland and in the Labrador Sea with globally less sea ice in the MH as compared to the Holocene period. Indeed, several sea ice condition reconstructions based on driftwood deposits and on beach ridges show rare or absent multiyear sea ice in the $\mathrm{MH}$ as far north as the northern coasts of Greenland (Bennike, 2004; Möller et al., 2010; Funder et al., 2011) and Ellesmere Island (England et al., 2008), while these coastlines are presently permanently surrounded by pack ice (Polyak et al., 2010). Note that according to (Olsen et al., 2012), northern Greenland displayed no strong signal in sea ice in the MH as compared to the whole Holocene, since this period was experiencing a shift in climate from warmer conditions associated with a reduced sea ice towards colder conditions and more prolonged winter ice cover. This MH shift is also recorded through the analysis of $\mathrm{IP}_{25}$ in two sediment cores collected from the continental slope of West Spitsbergen. They display lower sea ice cover in the MH as compared to the end of the records covering the very late Holocene (Müller et al., 2012), consistent with the negative sea ice concentration anomalies of core id 17.

Further south, along the East Greenland Shelf, the reconstruction of Müller et al. (2012) based on $\mathrm{IP}_{25}$ and brassicasterol and the reconstruction of Jennings et al. (2002) based on ice-rafted detritus are consistent and highlight relatively low sea ice cover in the MH as compared to the PI period and the whole Holocene period, respectively. The dinocyst-based reconstruction from de Vernal et al. (2013a) adjacent from the previous reconstructions (id 15) shows no change at $6 \mathrm{ka}$ as compared to the PI period.

Off northern Iceland, the extent of drift ice seemed to reach a minimum in the $\mathrm{MH}$ relative to the past $10 \mathrm{kyr}$, according to a reconstruction based on the presence of quartz (Andrews et al., 2009). Finally, since there is no other independent sea ice proxy-record, the positive sea ice concentration anomalies displayed in the Barents Sea (id 18) cannot be confirmed or rebutted.

The conclusions derived from the dinocyst-based reconstructions of de Vernal et al. (2013a) are thus generally qualitatively confirmed by other proxy-based reconstructions, even if some discrepancies exist. However, out of the 18 proxy-based reconstructions, only four (id 2, 4, 5, and 7 on Fig. 1) have a larger signal than their error, i.e. does not have zero within the error bar. This has two implications for the following of this study to keep in mind. First, the potential of this data set to test the models' performance is weak and, second, the constraint applied on the LOVECLIM results during the process of data assimilation will not be large.

\subsection{Simulations without data assimilation}

Here, the simulated sea ice signal in the MH on a large scale is first studied, before analysing the sea ice cover for the model grid points that contain the quantitative sea ice proxy record of de Vernal et al. (2013a) displayed in Fig. 1. We assume that the spatial representativeness of each core corresponds to the matching grid cell of each model, while the latter have different spatial resolutions. We mainly focus on 8 of the 18 available cores (id 1-5, 15, 17 and 18) because the other ones are located south of the simulated sea ice edge for most of the GCMs and LOVECLIM for both the MH and the PI periods and thus display no change in sea ice concentration. Since the proxy records are calibrated to represent annual means, we primarily focus on the annual means of the models, although seasonal means are also considered in order to get a better understanding of the processes that drive the simulated sea ice cover.

As compared to the reference period AD 1850-1900, model results show globally lower annual mean sea ice concentrations for the MH in the Arctic (Fig. 2a for LOVECLIM and Fig. A1 for the other models), although the signal is weak for most of the models and the ice edge is virtually at the same location for both periods. The annual averages actually 


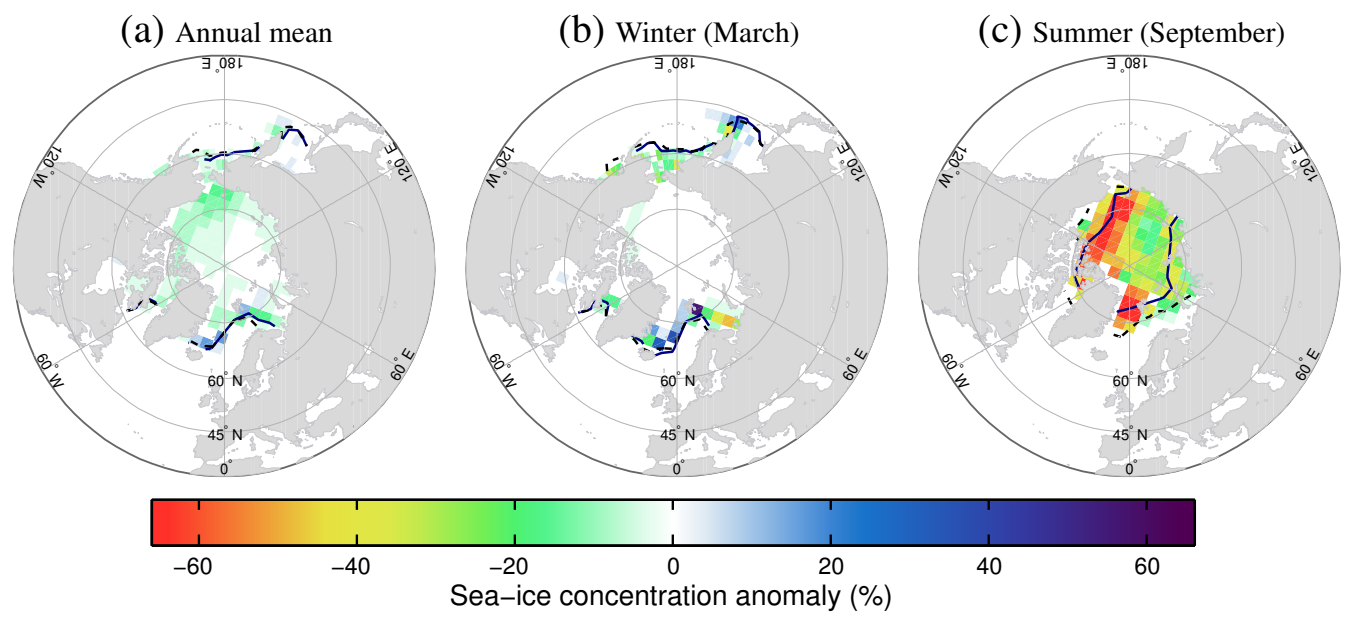

Figure 2. Mean annual, winter (March) and summer (September) MH sea ice concentration anomalies (in \%, with respect to the PI reference period) and location of the ice edge for $6 \mathrm{ka}$ (solid lines) and for the PI period (dashed lines), defined as $15 \%$ concentration limits, as simulated by LOVECLIM without data assimilation.

hide larger differences in sea ice that occur in different seasons between the MH and the PI period. In winter, the sea ice tends to be more variable (Fig. $2 b$ for LOVECLIM and Fig. A2), nearly all models simulating some regions with a higher ice extent and others with a sea ice retreat, but with different patterns. In summer, the agreement is better with a significantly decreased sea ice concentration in all the sectors (Fig. 2c for LOVECLIM and Fig. A3 for the other models).

When looking at the locations of the sea ice reconstructions, the simulated signal is homogeneous over the Chukchi Sea (id 1 and 2) and the CAA (id 3-5), where all models depict weak negative anomalies (Fig. 3). This annual decrease in sea ice cover is mainly due to a lower sea ice concentration in summer in response to the relatively strong increase in insolation (on average $24 \mathrm{~W} \mathrm{~m}^{-2}$ for these regions; Fig. $4 \mathrm{c}$ ). To a lesser extent, fall also contributes to the decrease in annual sea ice cover especially in the Chukchi Sea, despite a dwindling insolation at $6 \mathrm{ka}$ (on average $-7 \mathrm{~W} \mathrm{~m}^{-2}$; Fig. 4d). This can be explained by the inertia of the system: higher summer insolation leads to a decrease in ice thickness and concentration in summer and thus larger oceanic heat fluxes during the following seasons (Manabe and Stouffer, 1980; Renssen et al., 2005; Boé et al., 2009; Crespin et al., 2012). No change in winter and spring sea ice cover is simulated over the Chukchi Sea and the CAA (Fig. 4a and b), these regions being then fully covered by sea ice and far from the ice edge (Fig. $2 b$ for LOVECLIM and Fig. A2 for the other models).

In the Barents Sea (id 18), the annual mean sea ice concentration is also lower in the MH compared to the PI period for the majority of the models (Fig. 3). However, the spread is larger than in the Chukchi Sea and two GCMs (CCSM4 and MIROC-ESM) even display positive anomalies. These latter models show higher MH sea ice concentration all year long with a maximum in spring which is consistent with the decreased insolation during this season $\left(-2.79 \mathrm{~W} \mathrm{~m}^{-2}\right)$. As for the other models which show negative annual sea ice concentration anomalies, they have their maximum decrease in sea ice in fall (CSIRO-Mk3-6-0, MRI-CGCM3, BCC-CSM11 and LOVECLIM; Fig. 4d) or in winter (CNRM-CM5, HadGEM2-CC, HadGEM2-ES and MPI-ESM-P; Fig. 4a). This contrasts with the previous situation since the maximum decrease in sea ice concentration appears delayed compared to the western Arctic and inconsistent with the insolation anomalies during the corresponding season $\left(-7.92 \mathrm{~W} \mathrm{~m}^{-2}\right.$ in fall and $0.04 \mathrm{~W} \mathrm{~m}^{-2}$ in winter). However, this can easily be explained by the mean state of the models, i.e. the simulated sea ice concentration in absolute values for the PI period. In summer, the models cannot melt any sea ice in the MH compared to the PI since most of them depict almost ice-free conditions over the Barents Sea (Fig. 5). The models that have their maximum decrease in sea ice in fall are the ones that already display a reasonable ice cover during that season for the PI. The other models have a later beginning of the ice season (November-December) for the PI, and thus a maximum reduction at that time.

The annual mean simulated MH sea ice concentration is also lower in Fram Strait (id 17) and in the Greenland Sea (id 15) as compared to the PI values. As in the Barents Sea, the changes in insolation alone cannot explain the simulated sea ice cover fluctuations as they vary both in timing and in magnitude between the models. The simulated mean state likely plays a role there too but the interpretation seems more complex.

As compared to the signal of the proxy-based reconstructions, the simulated sea ice concentration signal is weaker (the average of all the modelled annual mean anomalies over the studied locations is $3.3 \%$ compared to $6.5 \%$ for the 


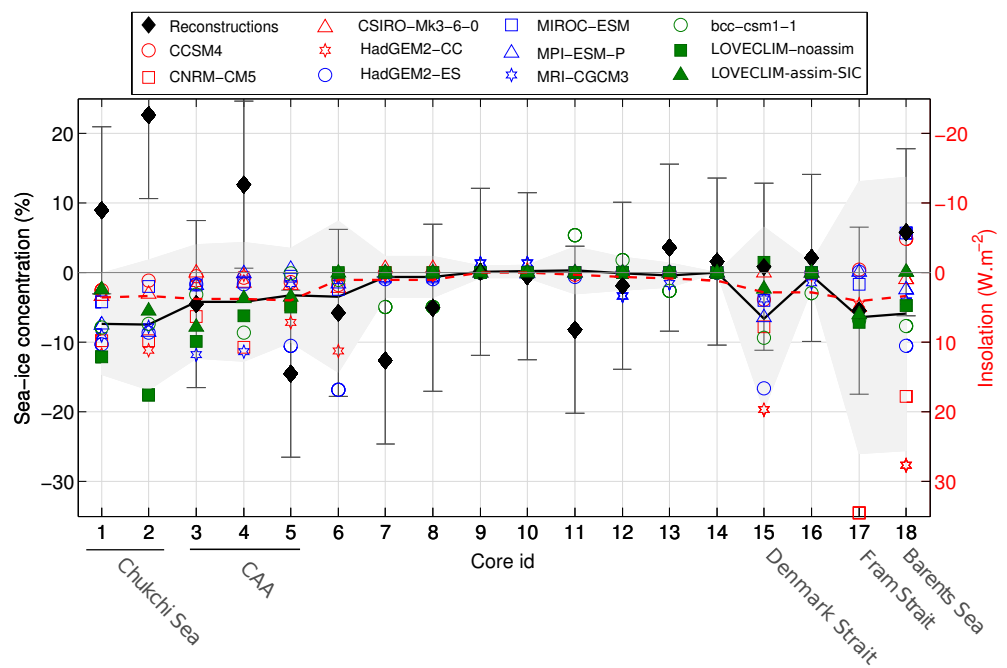

Figure 3. Mid-Holocene annual mean sea ice concentration anomalies (in \%) for the proxy-based reconstructions of de Vernal et al. (2013a) (black diamonds with error bars) and the corresponding climate models results. The thick black line is the model mean. The grey shaded areas are the model mean \pm 2 standard deviations. The dashed red line represents the annual mean insolation at each location studied (in $\mathrm{W} \mathrm{m}^{-2}$ ) and corresponds to the reversed right axis. The reference period is AD 1850-1900.

(a) Winter (DJF)

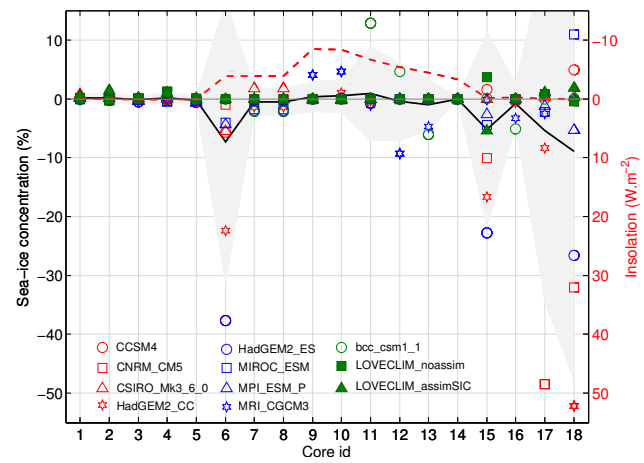

(c) Summer (JJA)

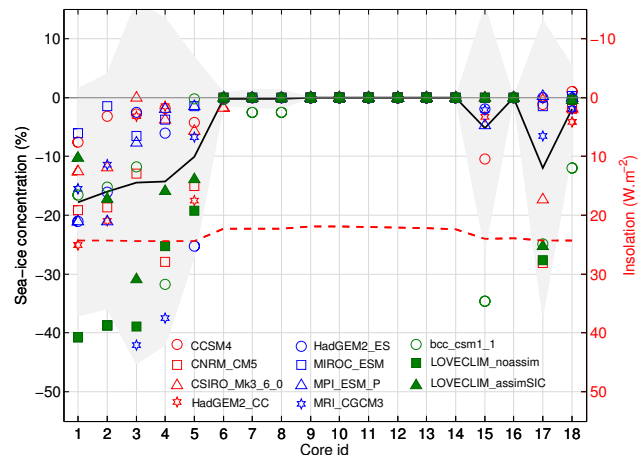

(b) Spring (MAM)

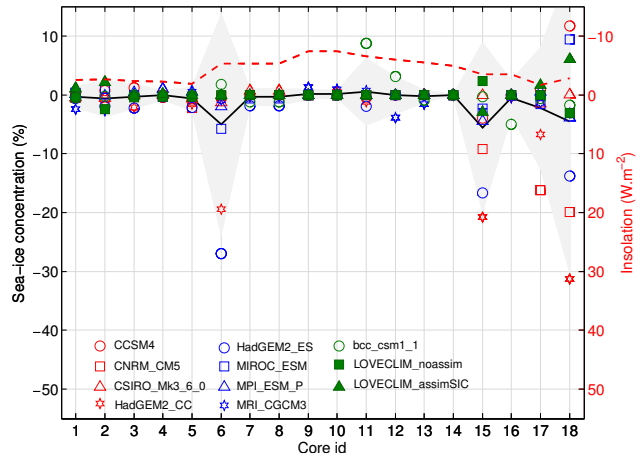

(d) Autumn (SON)

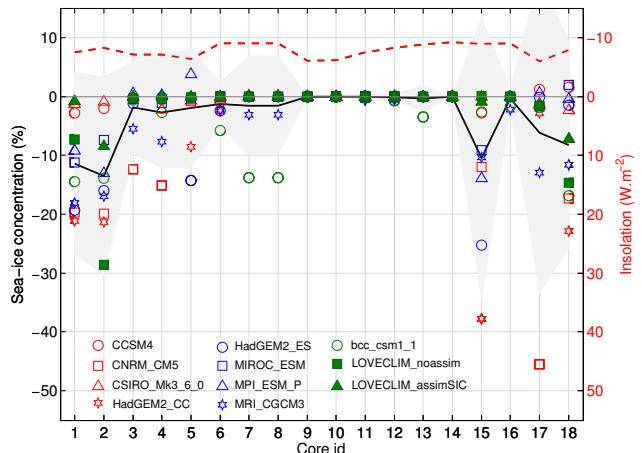

Figure 4. Mid-Holocene seasonal mean sea ice concentration anomalies (in \%) for the climate model results corresponding to the core locations. The thick black line corresponds to the model mean. The grey shaded areas are the model mean \pm 2 standard deviations. The dashed red line represents the seasonal mean insolation at each studied location (in $\mathrm{W} \mathrm{m}^{-2}$ ) and corresponds to the reversed right axis. The reference period is AD 1850-1900. 
(a) Mid-Holocene

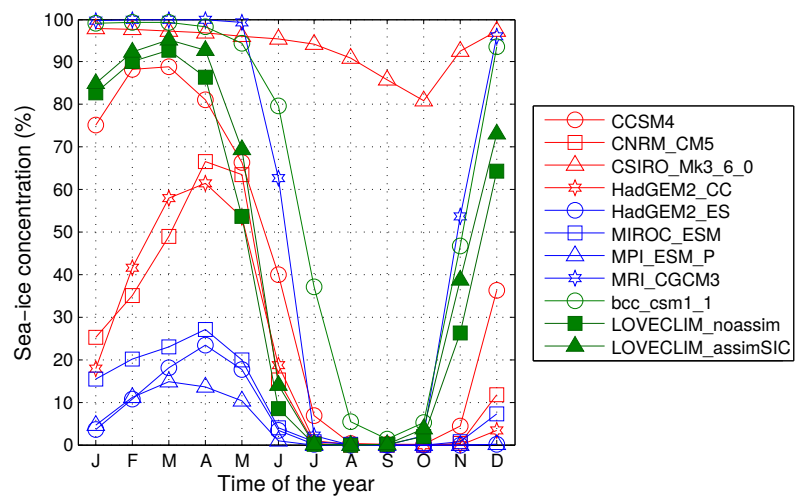

(b) Pre-industrial

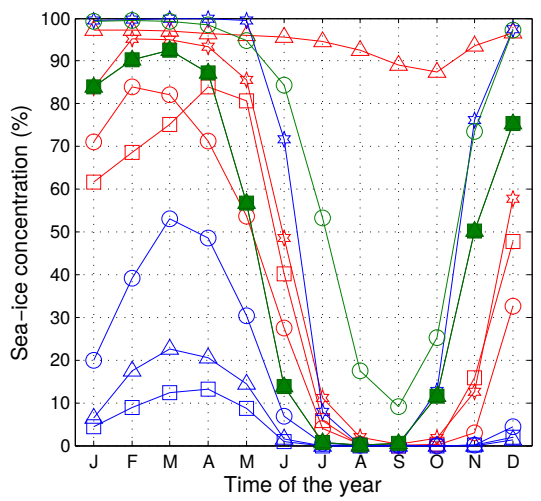

Figure 5. Mid-Holocene (6 ka) and pre-industrial (AD 1850-1900) mean seasonal cycles of sea ice concentration (in \%) in the Barents Sea (at the location of the proxy-based reconstruction id 18).

proxy data; red lines on Fig. 6) and spatially more homogeneous (the average of standard deviations equals $4.5 \%$ compared to $8.8 \%$ ). The most noticeable discrepancy between models and data occurs in the Chukchi Sea, where all models simulate a lower sea ice concentration while the two proxy-based reconstructions show the opposite (Fig. 3). This could be partly due to the misrepresentation of the exchanges between the Arctic and the Pacific through the Bering Strait by the models. The very heterogeneous sea ice cover recorded over the CAA is also not reproduced by the models, but this was expected given that the complex circulation pattern has local effects on sea ice (e.g. Lietaer et al., 2008). In the Fram Strait, the sea ice record agrees with the model mean signal. This is not the case in the Denmark Strait and in the Barents Sea where the mean simulated sea ice anomalies are negative while the proxybased reconstructions show positive anomalies (Fig. 3), even if some models are able to reproduce the sign and magnitude of the reconstructed signal.

A more quantitative way to study the (dis)agreement between models and data is to compute the root mean square error (RMSE) between the results of each climate model and the proxy-based sea ice reconstructions (Fig. 6). The values range from 9 to $14 \%$. The models are in better agreement amongst themselves than with the proxy-based reconstructions since the difference in RMSE between any of the models is smaller (largest difference is equal 5\%) than any RMSE using the reconstruction. Furthermore, assuming no change in sea ice concentration between the MH and the PI period provides an even lower RMSE than any of the models (this is equivalent to computing the RMSE using a constant field of anomalies being equal to zero; see the purple bar on Fig. 6). However, those RMSE should be analysed with caution. First, the calculation is performed based on the difference between each proxy-based reconstruction and the simulated sea ice in the corresponding grid cell. This means

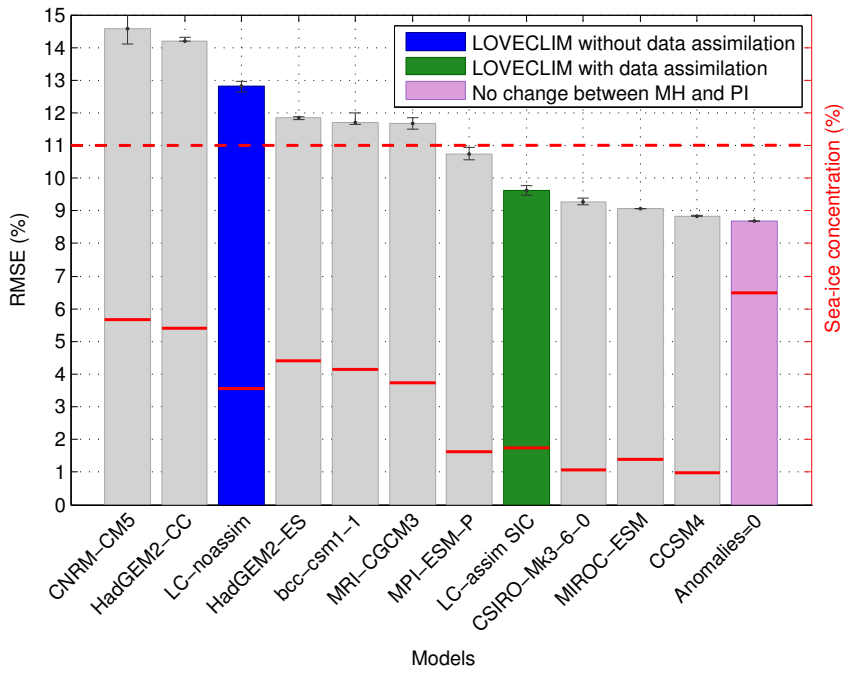

Figure 6. Ranked RMSE between the MH sea ice anomalies (reference period AD 1850-1900) simulated by each model and the proxy-based reconstructions. The error bars correspond to the range of the RMSE when changing the reference period to AD 1850-1875 and AD 1875-1900. The purple bar is the RMSE computed assuming no change between the $\mathrm{MH}$ and the PI and is thus a measure of the mean signal of the data. The dashed red line is the estimate of the mean data error (to be read with the right axis). The red lines are the mean signals of the models and the data (purple bar), both estimated as the mean of the absolute value of the difference between the $\mathrm{MH}$ and the PI period (to be read with the right axis).

that a small shift in the spatial structures in the models or small biases in the mean state can lead to large errors. More importantly, the difference between model and data is of the same order as the uncertainty of the reconstructions. The signal depicted by the proxy-based reconstructions appears larger and more heterogeneous but we could not determine with good confidence which part of this discrepancy is due 
to the non-climatic noise present in the proxies and in the uncertainties in the reconstruction method, or to the biases of models results. This prevents estimating explicitly the models' skills as done, for instance, in Hargreaves et al. (2013) and in Mairesse et al. (2013) for temperature data. The main robust conclusion is that models and reconstructions agree that the changes between the MH and the PI period annual mean sea ice concentration are relatively weak.

On a larger scale, the atmospheric circulation changes may explain the spatial structure of the simulated sea ice anomalies in various models. Here, the atmospheric circulation is inferred from the surface pressure of the GCMs because the geopotential heights were not available for all of them at the time of the analysis. For the LOVECLIM simulations, we preferred using the geopotential heights at the pressure level $800 \mathrm{hPa}$ because it is a direct dynamical variable that gives more reliable results than the surface pressure. We have checked the models for which both the geopotential heights and the surface pressure were available and, qualitatively, these two variables give the same atmospheric patterns.

The simulated atmospheric circulation changes between the $\mathrm{MH}$ and the PI are relatively weak, and appear to have a relatively complex spatial structure (Figs. 7 and 8). Overall, the models disagree on many aspects of the changes, although some common atmospheric patterns can be found in spring (a trend similar to a more negative Arctic Oscillation regime), summer and autumn (higher geopotential height over the northern Pacific and globally lower over the Eurasian continent) (not shown). Depending on the model selected, the atmospheric circulation can initially exacerbate or mitigate the decreased sea ice cover due to the higher summer insolation over the Chukchi Sea. Indeed, some models display atmospheric circulation patterns that tend to induce some sea ice convergence towards that region (e.g. CCSM4, MRI-CGCM3, MIROC-ESM) or to push it away (e.g. LOVECLIM no assim, BCC-CSM1-1). Nevertheless, the link between atmospheric circulation and sea ice concentration is hard to estimate because of the likely dominant role of the thermodynamical response to insolation changes.

The role of the atmospheric circulation does not appear to be clearer in the Barents Sea, where the positive annual anomalies displayed by CCSM4 and MIROC-ESM cannot be explained by the respectively southerly and easterly wind anomalies simulated there, although the northerly winds simulated by CNRM-CM5 could explain the large negative sea ice anomalies simulated by this model. The different responses of the models appear thus to imply too many processes to be analysed in the present framework using available diagnostics. The potential role of atmospheric circulation will be more deeply analysed in the next section, involving data assimilation. In that particular case, model physics is the same and the only differences are the ones induced by the data constraint, which manifests itself in our experiments mainly through atmospheric circulation changes.

\subsection{Simulations with data assimilation}

Without assimilation, the sea ice concentration simulated by LOVECLIM shows some clear differences with the best estimates given by the reconstructions of de Vernal et al. (2013a) (Fig. 6), especially in the Chukchi Sea where the model displays the most negative anomalies among all models while the proxy-based reconstructions show positive ones (Fig. 3). As expected, data assimilation leads to better agreement with the majority of the proxy-based reconstructions (compare the green triangles in Fig. 3 with the green squares). In particular over the Chukchi Sea (id 1 and 2), LOVECLIM with data assimilation has an annual mean ice concentration higher than LOVECLIM without data assimilation, respectively 9.7 and $12.1 \%$ where cores 1 and 2 are located. This strong increase is, however, not sufficient to get positive anomalies, since over that region, the increase of the simulated sea ice can only occur in summer and autumn, the rest of the year being already fully covered by sea ice in the MH. However, the significantly higher insolation in summer and its lingering effect in autumn prevents any massive increase in sea ice. Furthermore, the proxy-based reconstruction uncertainty is larger than the signal depicted by the first core, which leads to a constraint too weak to get positive anomalies.

Over the CAA (id 3-5), the signal of the proxy-based reconstructions is too heterogeneous to be simulated by LOVECLIM. Compared to the simulation without data assimilation, the simulation with data assimilation provides a slightly increased annual mean sea ice concentration because of a less reduced summer sea ice. Yet the annual anomalies are still negative, which is consistent with two out of the three cores located there (id 3 and 5). In the Denmark Strait (id 15), the consistency between LOVECLIM and the proxy-based reconstruction is lower after data assimilation, due to a decreased winter and spring sea ice concentration (Fig. 4a and $b$ ). However, the simulated sea ice stays within the range of the proxy-based reconstruction error.

Further north, in Fram Strait (id 17), LOVECLIM without assimilation is very close to the data and the assimilation has virtually no effect on the simulated sea ice. Eventually, the simulated annual sea ice concentration at the Barents Sea (id 18) is increased by $4.8 \%$ in the simulation with data assimilation compared to the simulation without assimilation. In this way, LOVECLIM gets closer to the data but fails to simulate the positive anomaly necessary to really be consistent with the data that shows an increase in sea ice concentration by $5.7 \%$. Since there is a lack of other independent sea ice proxy records, this last proxy-based reconstruction of de Vernal et al. (2013a) could not be validated, even qualitatively. As it is the only core on the Eurasian coast and is, therefore, potentially important to the whole assimilation process, its effect has been tested in additional sensitivity experiments. However, changing its sea ice concentration value (to 0 and $-20 \%$ instead of $5.75 \%$ ) does not lead to large changes in sea ice concentration at the other core locations or 
(a) BCC-CSM1-1

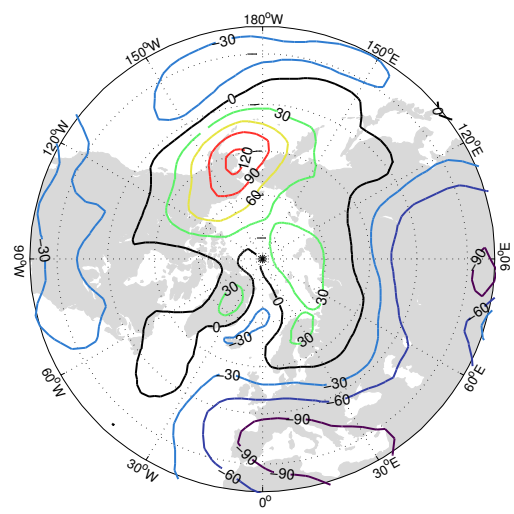

(d) CSIRO-Mk3-6-0

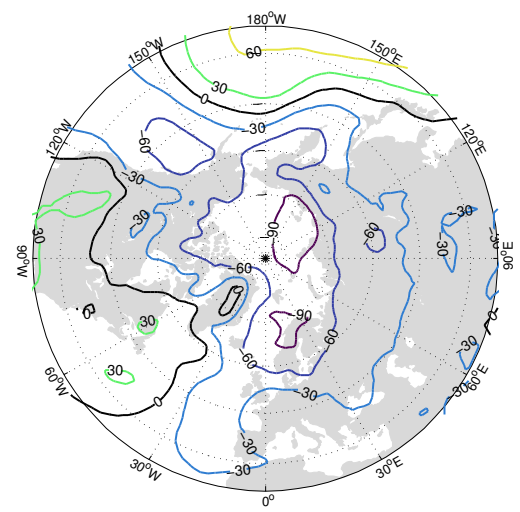

(g) MIROC-ESM

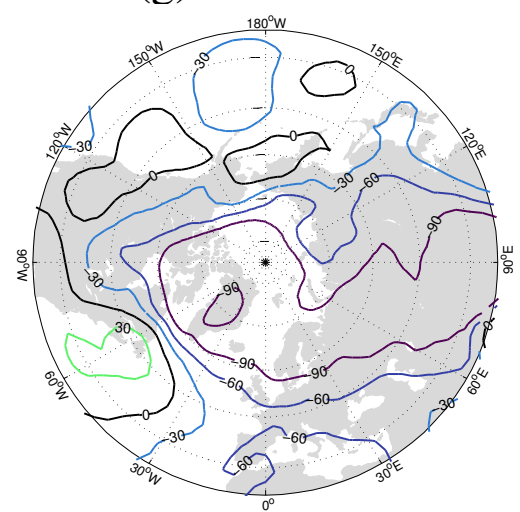

(b) CCSM4

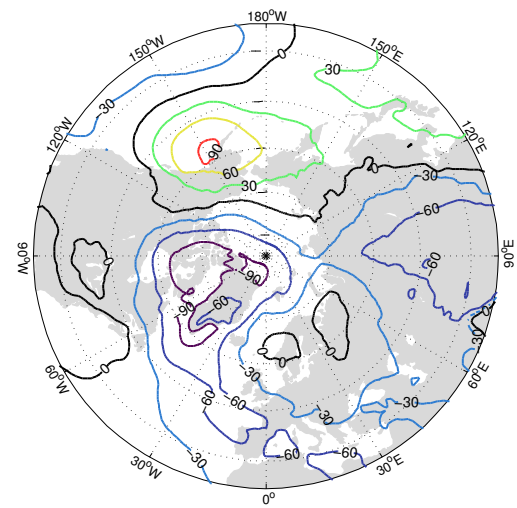

(e) HadGEM2-CC

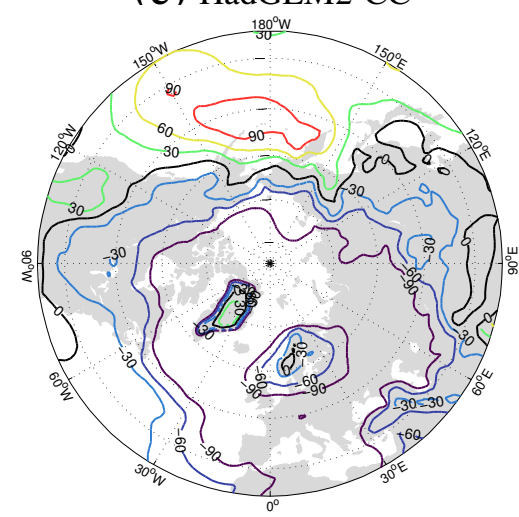

(h) MPI-ESM-P

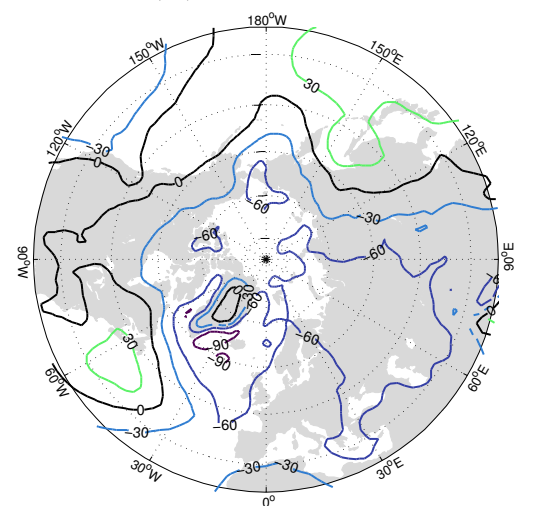

(c) CNRM-CM5

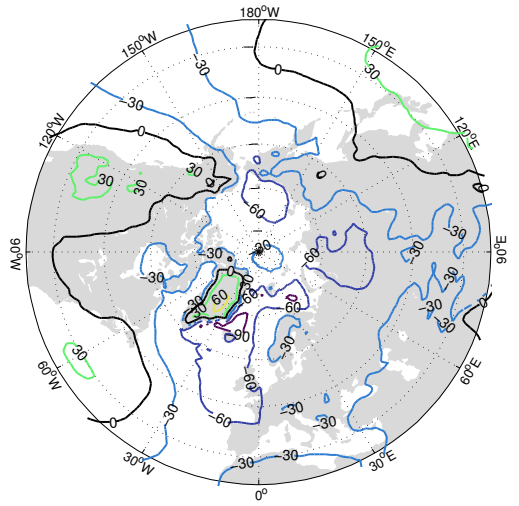

(f) HadGEM2-ES

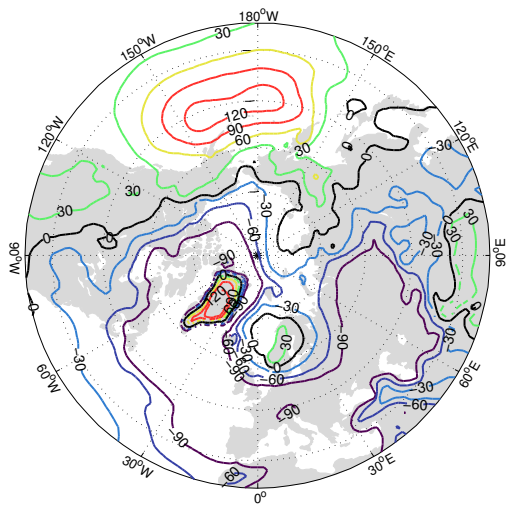

(i) MRI-CGCM3

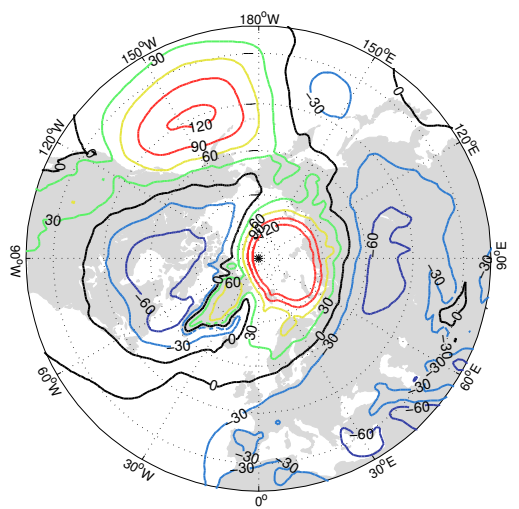

Figure 7. Annual mean surface pressure anomalies (in Pa) simulated by the GCMs for the MH (reference period AD 1850-1900).

in the RMSE of the model (not shown). This core is thus not critical to the assimilation process on a large scale, LOVECLIM being able to fit the new core values locally without significantly altering the sea ice results somewhere else.

Overall, the data assimilation leads to a modest decrease of the RMSE (9.6\% compared to $12.8 \%$; Fig. 6), but the agreement between LOVECLIM with data assimilation and the sea ice reconstruction is still far from being perfect. This is not surprising considering first the uncertainty of the data, which is of the same order of the signal in many locations, making the constraint relatively weak. The data assimilation method used here does not consist of changing the physics or parameters of the model but instead of selecting the simulations from among an ensemble that best fit the 
(a) Without data assimilation

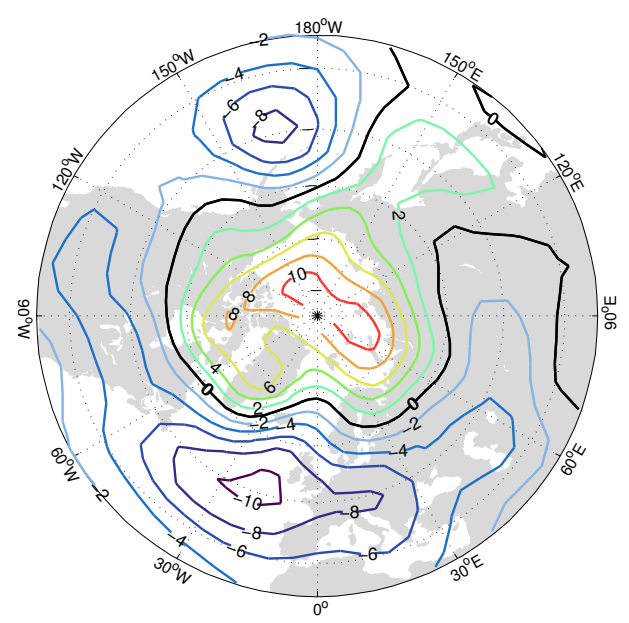

(b) With data assimilation

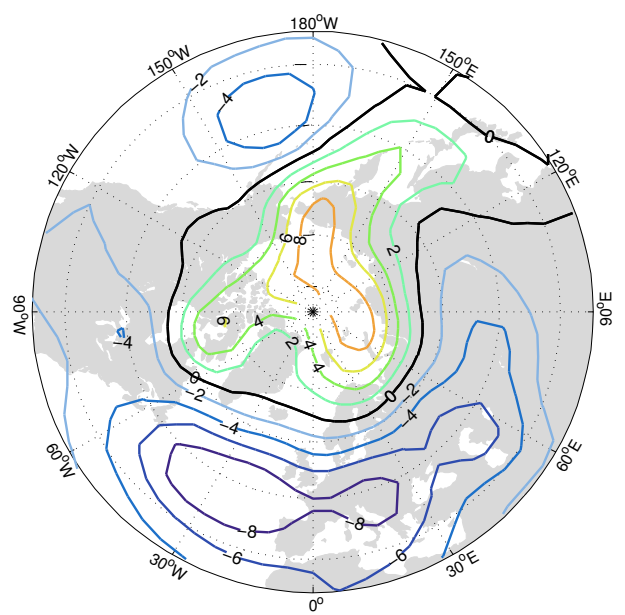

Figure 8. MH annual geopotential height anomalies (in $\mathrm{m}$ ) at $800 \mathrm{hPa}$ simulated by (a) LOVECLIM without assimilation and (b) LOVECLIM with assimilation of sea ice proxy data. The reference period is AD 1850-1900.

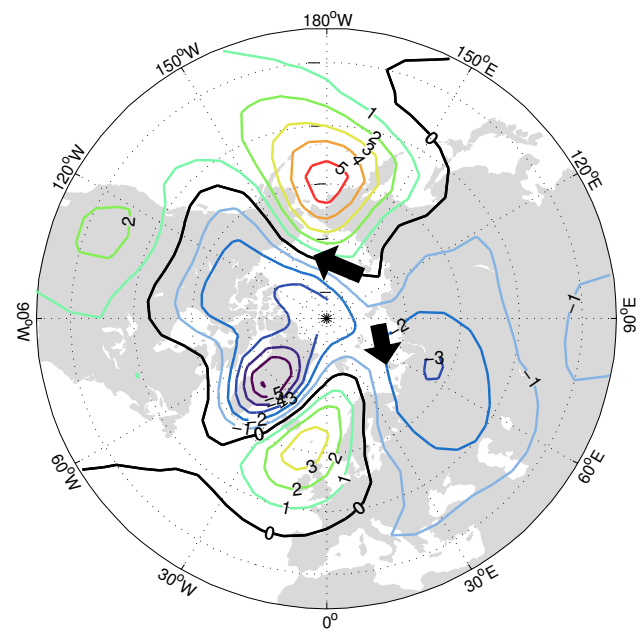

Figure 9. Difference between the geopotential height anomalies (in $\mathrm{m})$ at $800 \mathrm{hPa}$ of LOVECLIM with sea ice data assimilation and LOVECLIM without data assimilation. The black arrows show the flow responsible for the change in sea ice at the Barents Sea and the Chukchi Sea.

data. Consequently, the potential to significantly modify the way LOVECLIM simulates the sea ice for the MH is limited. Furthermore, the spatial resolution is rather coarse in LOVECLIM and, therefore, it cannot take into account small spatial scale processes potentially dominant over regional processes for some records.

The improved consistency between the simulation with sea ice data assimilation and the sea ice proxy-based reconstructions is associated mainly with higher sea ice concentration in the Chukchi Sea and in the Barents Sea. This is achieved through changes in the atmospheric circulation. Indeed, the higher pressure anomaly centred on the Aleutians in the simulation with data assimilation compared to the simulation without data assimilation leads to a cooling in the Chukchi Sea and to a convergence of sea ice in that region (Fig. 9). On the other side of the Arctic, the lower pressure anomaly centred on Russia is responsible for a cooling over the Barents Sea and thus leads to the increased simulated sea ice where core 18 is located.

\section{Conclusions}

We have compared new quantitative reconstructions of mean annual sea ice concentration in the MH with models output. Overall, the sea ice changes between the MH and the PI period are relatively weak both in the simulations and the reconstructions but they are weaker and spatially more homogeneous in models. The simulated ice changes are higher for individual seasons, with a relatively strong sea ice retreat in summer and a more variable sea ice during winter. This underlines the need for quantitative seasonal reconstructions for a more comprehensive model-data comparison in the future.

A general agreement between models and proxy-based reconstructions is found in the Labrador Sea while a large discrepancy occurs in the Chukchi Sea, where models are not able to reproduce the relatively high sea ice concentration reconstructed for the MH compared to the PI period. However, the uncertainty of the reconstructions, which is of the same order as the changes, prevents a precise evaluation of the models' skills on a regional scale.

Over the Chukchi Sea, the increased summer insolation appears to be a dominant driver for the simulated sea ice changes, while atmospheric circulation can mitigate or exacerbate the decrease in sea ice concentration. Between 
Greenland and the Barents Sea, the simulated sea ice concentration is more variable amongst models meaning that the agreement between models and data depends on the model considered. Over the whole Arctic, but particularly in these regions, the mean state of the models influences the timing of the simulated sea ice changes with a reduction of the MH sea ice concentration compared to PI values obviously only at the time when there is already sea ice in the PI. In addition to the role of insolation and to the link between the mean state and the model response, it is difficult in the present framework to precisely identify the mechanisms that control the simulated sea ice concentration for all models.
When LOVECLIM is constrained to follow the signal recorded in the proxy-based reconstructions using data assimilation, the resulting simulation shows overall a better agreement with data. This is mainly due to a decrease in the magnitude of the southerly winds in the Barents Sea and to stronger westerlies in the Beaufort and the Chukchi seas. The agreement between model results and proxy-based reconstructions is, however, still far from perfect. This can be explained to some extent by the relatively small magnitude of the reconstructed signal compared to the uncertainties. The atmospheric circulation anomalies induced by data assimilation can then be viewed as the main process leading, qualitatively, to a better model-data agreement. A larger amplitude of this pattern would lead to smaller model-data discrepancies but the value obtained in our simulation is determined by the experimental design, in particular the selected data uncertainties. 


\section{Appendix A}

(a) BCC-CSM1-1

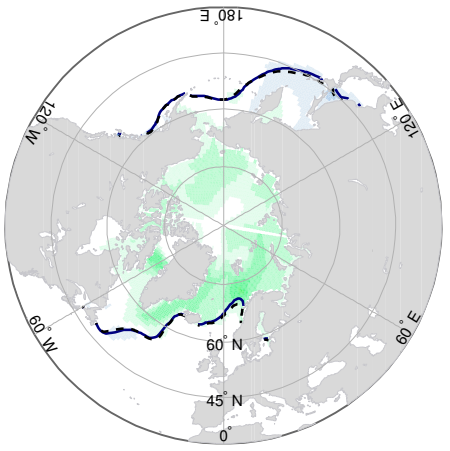

(d) CSIRO-Mk3-6-0

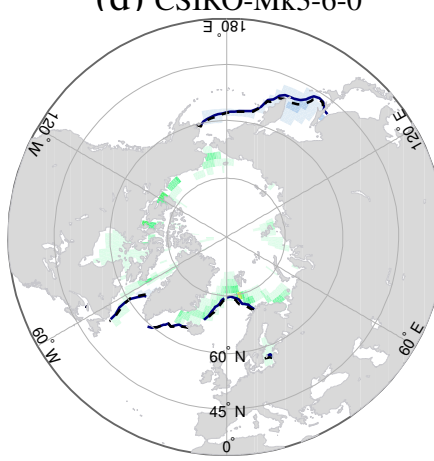

(g) MIROC-ESM

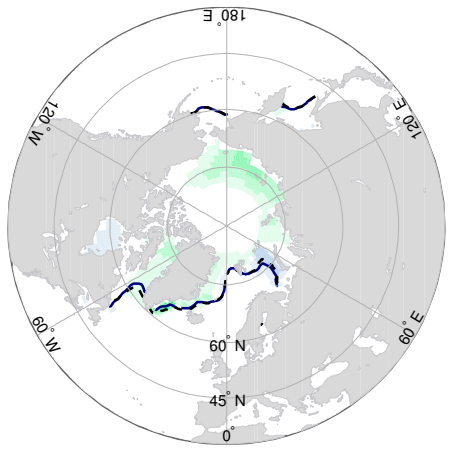

(b) CCSM4

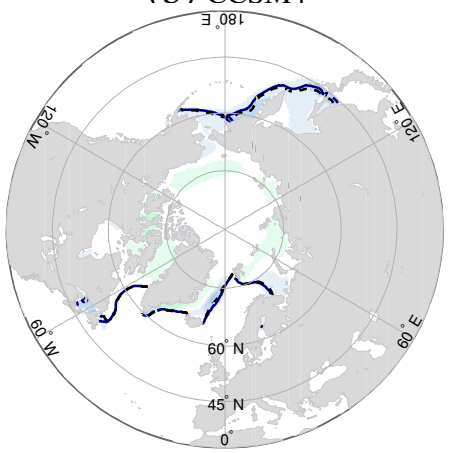

(e) HadGEM2-CC

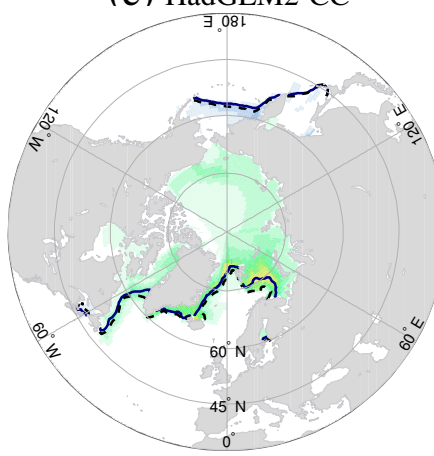

(h) MPI-ESM-P

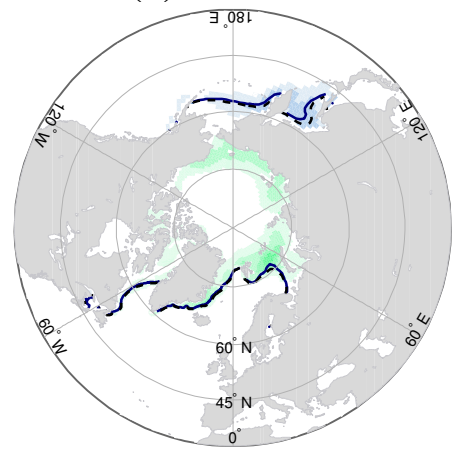

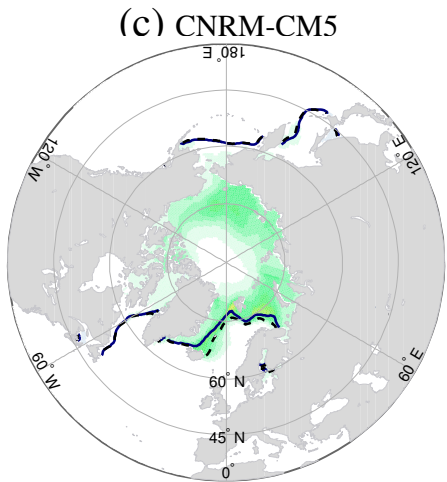

(f) HadGEM2-ES

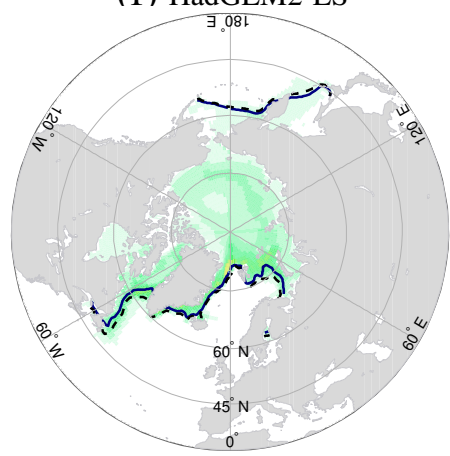

(i) MRI-CGCM3

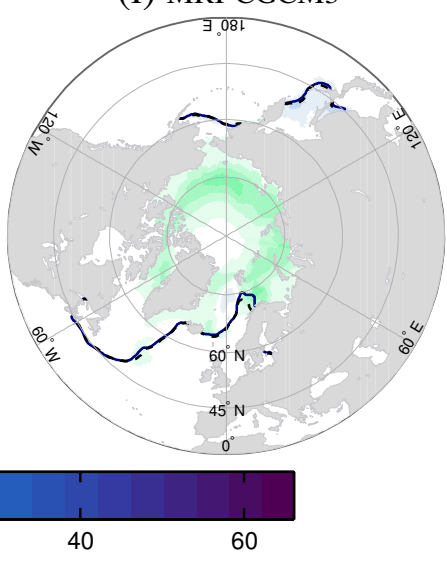

Figure A1. Mean MH annual sea ice concentration anomalies (in \%, with respect to the PI reference period) and location of the ice edge for $6 \mathrm{ka}$ (solid lines) and for the PI period (dashed lines), defined as $15 \%$ concentration limits. 
(a) BCC-CSM1-1

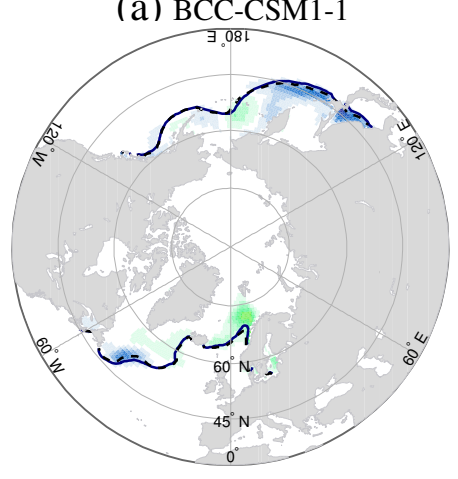

(d) CSIRO-Mk3-6-0

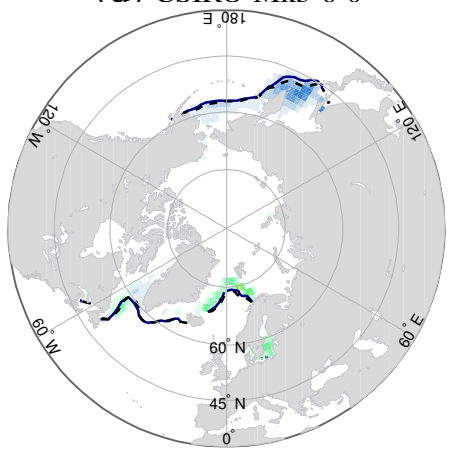

(g) MIROC-ESM

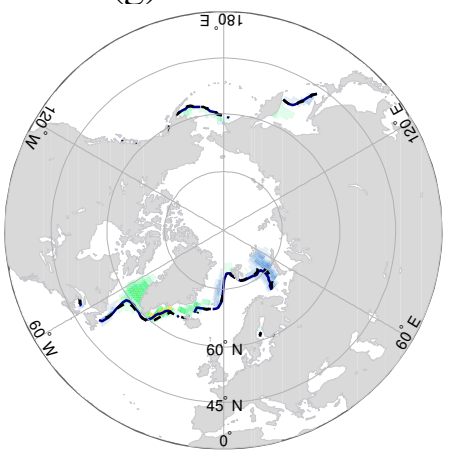

(b) CCSM4

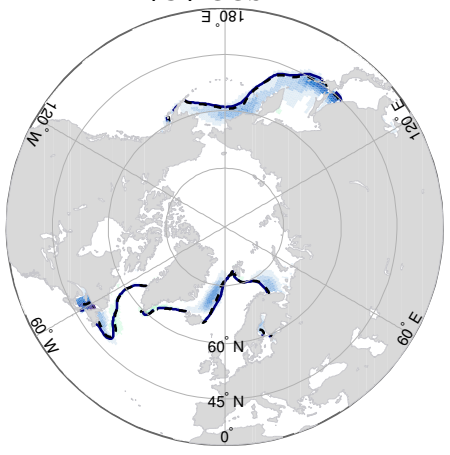

(e) HadGEM2-CC

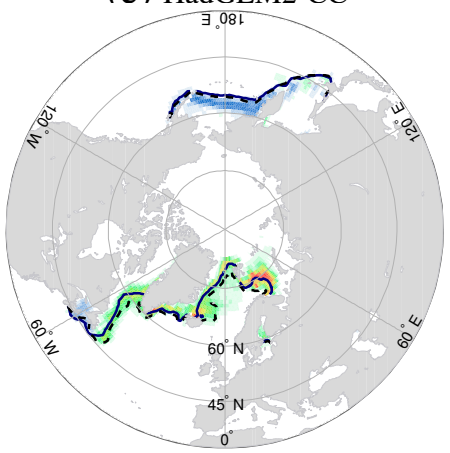

(h) MPI-ESM-P

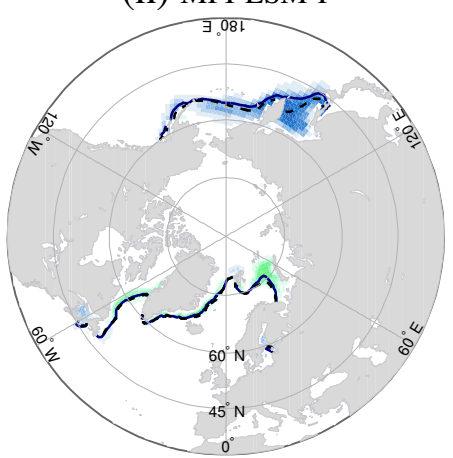

(c) CNRM-CM5

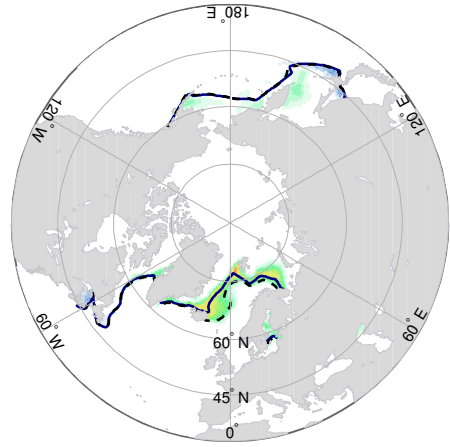

(f) HadGEM2-ES

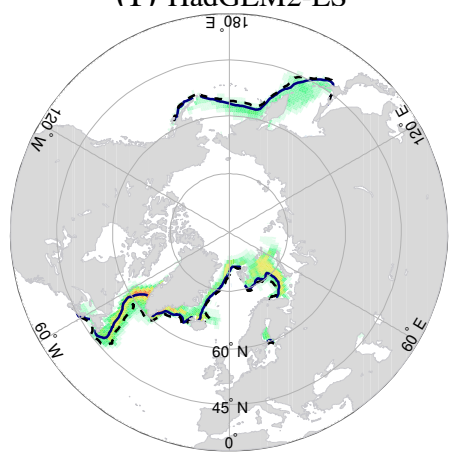

(i) MRI-CGCM3

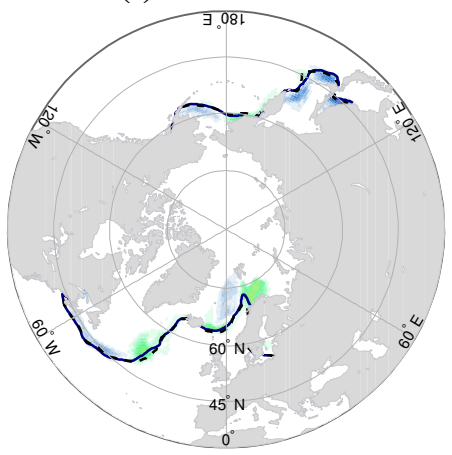

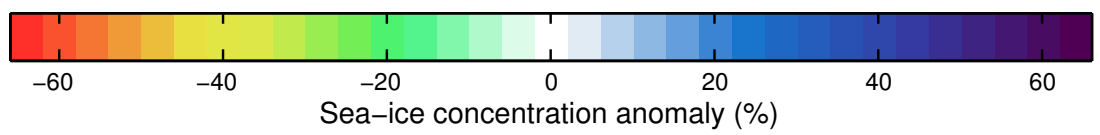

Figure A2. MH winter (March) sea ice concentration anomalies (in $\%$, with respect to the PI reference period) and location of the ice edge for $6 \mathrm{ka}$ (solid lines) and for the PI period (dashed lines), defined as the $15 \%$ concentration limits. 
(a) BCC-CSM1-1

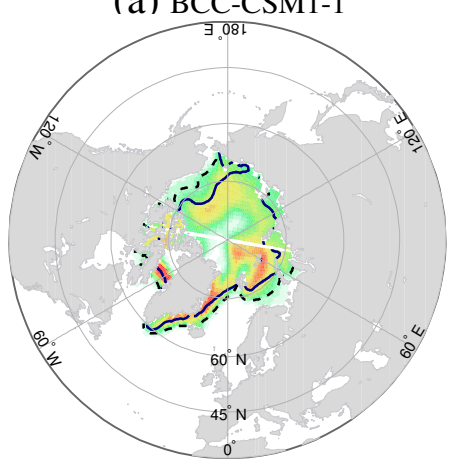

(d) CSIRO-Mk3-6-0

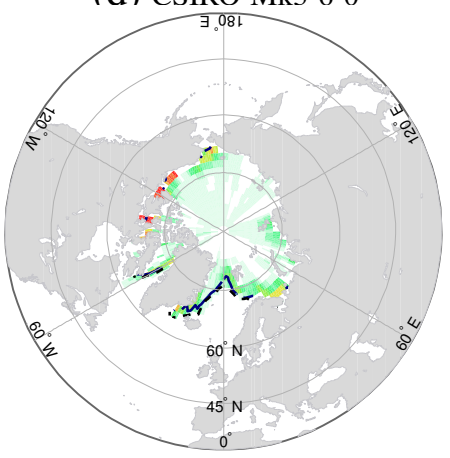

(g) MIROC-ESM

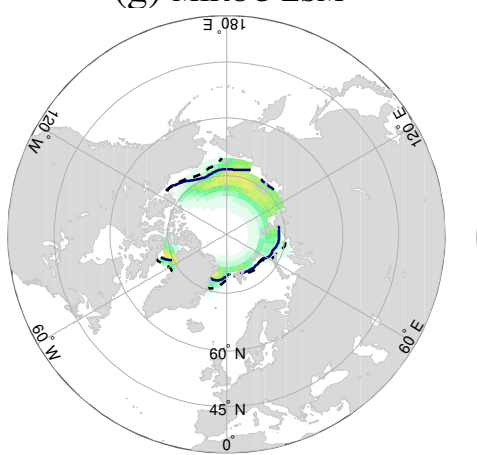

(b) CCSM4

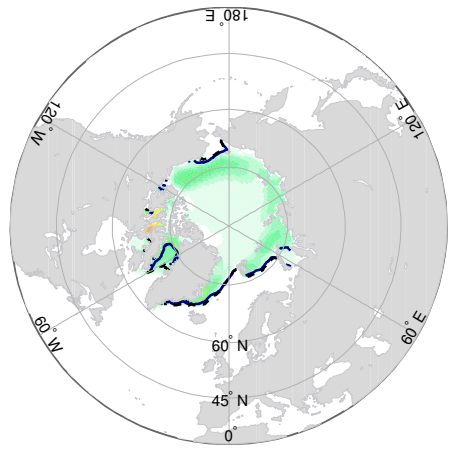

(e) HadGEM2-CC

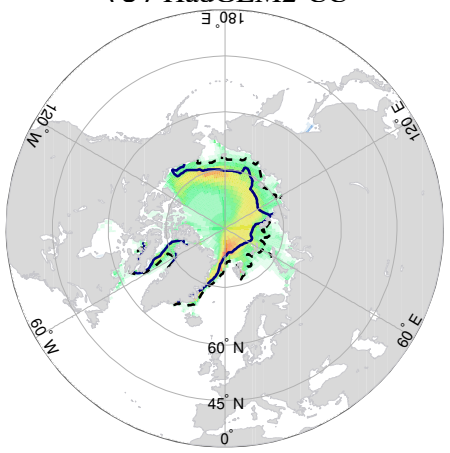

(h) MPI-ESM-P

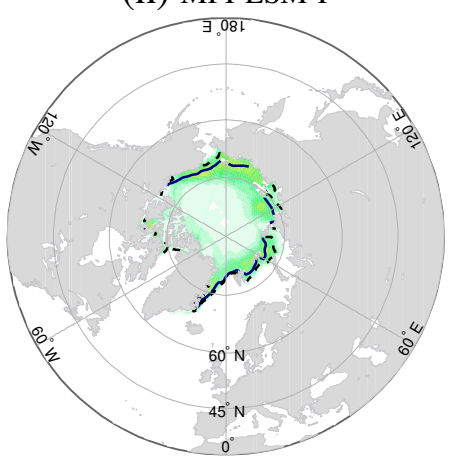

(c) CNRM-CM5

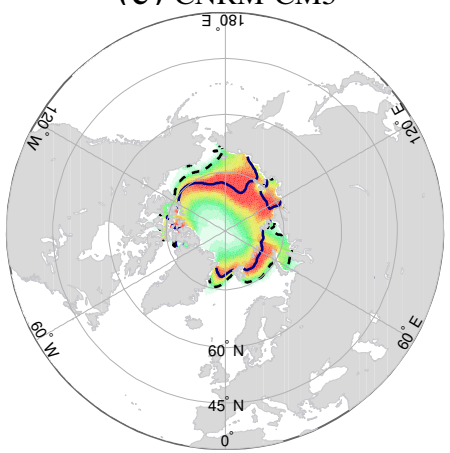

(f) HadGEM2-ES

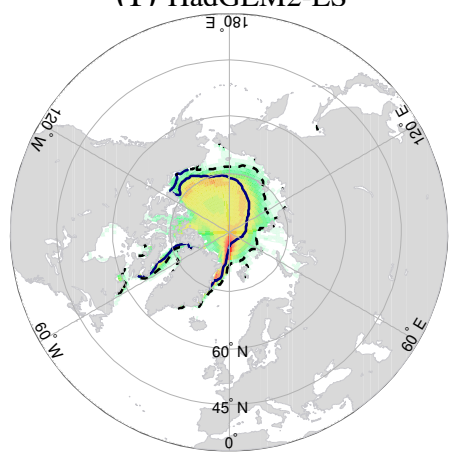

(i) MRI-CGCM3

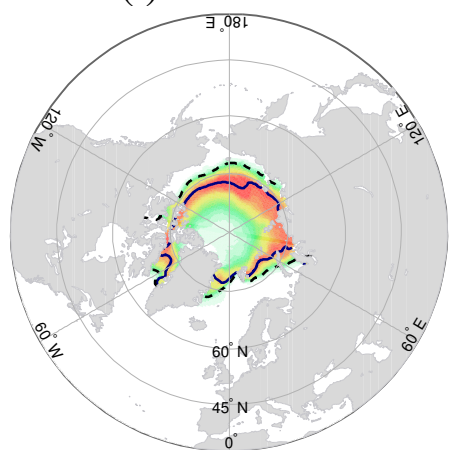

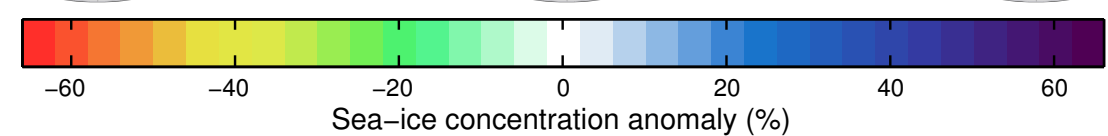

Figure A3. MH summer (September) sea ice concentration anomalies (in \%, with respect to the PI reference period) and location of the ice edge for $6 \mathrm{ka}$ (solid lines) and for the PI period (dashed lines), defined as $15 \%$ concentration limits. 
Acknowledgements. We thank the editor and two anonymous reviewers for valuable suggestions during the review process which improved the final version of this paper. We acknowledge all those involved in producing the PMIP an CMIP multi-model ensemble and all the climate modelling groups for making available their model output. We acknowledge the World Climate Research Programme's Working Group on Coupled Modelling, which is responsible for CMIP. For CMIP the US Department of Energy's Program for Climate Model Diagnosis and Intercomparison provides coordinating support and led development of software infrastructure in partnership with the Global Organization for Earth System Science Portals. The research leading to these results has received funding from the European Union's Seventh Framework programme (FP7/2007-2013) under grant agreement no. 243908, "Past4Future: Climate change - Learning from the past climate". Computational resources have been provided by the supercomputing facilities of the Université catholique de Louvain (CISM/UCL) and the Consortium des Equipements de Calcul Intensif en Fédération Wallonie Bruxelles (CECI) funded by FRS-FNRS. Hugues Goosse is senior research associate with the FRS/FNRS, Belgium. This is Past4Future contribution 66.

Edited by: V. Rath

\section{References}

Andrews, J. T., Darby, D., Eberle, D., Jennings, A. E., Moros, M., and Ogilvie, A.: A robust, multisite Holocene history of drift ice off northern Iceland: implications for North Atlantic climate, The Holocene, 19, 71-77, doi:10.1177/0959683608098953, 2009.

Atkinson, N.: A 10 400-Year-Old Bowhead Whale (Balaena mysticetus) Skull from Ellef Ringnes Island, Nunavut: Implications for Sea-Ice Conditions in High Arctic Canada at the End of the Last Glaciation, Arctic, 62, 38-44, 2009.

Belt, S. T., Vare, L. L., Massé, G., Manners, H. R., Price, J. C., MacLachlan, S. E., Andrews, J. T., and Schmidt, S.: Striking similarities in temporal changes to spring sea ice occurrence across the central Canadian Arctic Archipelago over the last 7000 years, Quaternary Sci. Rev., 29, 3489-3504, doi:10.1016/j.quascirev.2010.06.041, 2010.

Bennike, O.: Holocene sea-ice variations in Greenland: onshore evidence, The Holocene, 14, 607-613, doi:10.1191/0959683604hl722rr, 2004.

Berger, A.: Long-term variations of daily insolation and Quaternary climatic changes, J. Atmos. Sci., 35, 2363-2367, 1978.

Berger, M., Brandefelt, J., and Nilsson, J.: The sensitivity of the Arctic sea ice to orbitally induced insolation changes: a study of the mid-Holocene Paleoclimate Modelling Intercomparison Project 2 and 3 simulations, Clim. Past, 9, 969-982, doi:10.5194/cp-9-969-2013, 2013

Boé, J., Hall, A., and Qu, X.: Current GCMs' Unrealistic Negative Feedback in the Arctic, J. Climate, 22, 4682-4695, doi:10.1175/2009JCLI2885.1, 2009.

Braconnot, P., Otto-Bliesner, B., Harrison, S., Joussaume, S., Peterchmitt, J.-Y., Abe-Ouchi, A., Crucifix, M., Driesschaert, E., Fichefet, Th., Hewitt, C. D., Kageyama, M., Kitoh, A., Laîné, A., Loutre, M.-F., Marti, O., Merkel, U., Ramstein, G., Valdes, P., Weber, S. L., Yu, Y., and Zhao, Y.: Results of PMIP2 coupled simulations of the Mid-Holocene and Last Glacial Maximum -
Part 1: experiments and large-scale features, Clim. Past, 3, 261277, doi:10.5194/cp-3-261-2007, 2007.

Braconnot, P., Harrison, S. P., Kageyama, M., Bartlein, P. J., Masson-Delmotte, V., Abe-Ouchi, A., Otto-Bliesner, B., and Zhao, Y.: Evaluation of climate models using palaeoclimatic data, Nature Climate Change, 2, 417-424, doi:10.1038/nclimate1456, 2012.

Brovkin, V., Bendtsen, J., Claussen, M., Ganopolski, A., Kubatzki, C., Petoukhov, V., and An-dreev, A.: Carbon cycle, vegetation, and climate dynamics in the Holocene: Experiments with the CLIMBER-2 model, Global Biogeochem. Cy., 16, 1139 , doi:10.1029/2001GB001662.1., 2002.

Collins, W. J., Bellouin, N., Doutriaux-Boucher, M., Gedney, N., Halloran, P., Hinton, T., Hughes, J., Jones, C. D., Joshi, M., Liddicoat, S., Martin, G., O’Connor, F., Rae, J., Senior, C., Sitch, S., Totterdell, I., Wiltshire, A., and Woodward, S.: Development and evaluation of an Earth-System model - HadGEM2, Geosci. Model Dev., 4, 1051-1075, doi:10.5194/gmd-4-10512011, 2011.

Crespin, E., Goosse, H., Fichefet, T., Mairesse, A., and SallazDamaz, Y.: Arctic climate over the past millennium: Annual and seasonal responses to external forcings, The Holocene, 23, 321329, doi:10.1177/0959683612463095, 2012.

Cronin, T., Gemery, L., Briggs, W., Jakobsson, M., Polyak, L., and Brouwers, E.: Quaternary Sea-ice history in the Arctic Ocean based on a new Ostracode sea-ice proxy, Quaternary Sci. Rev., 29, 3415-3429, doi:10.1016/j.quascirev.2010.05.024, 2010.

de Vernal, A. and Rochon, A.: Dinocysts as tracers of sea-surface conditions and sea-ice cover in polar and subpolar environments, IOP Conference Series: Earth and Environmental Science, 14, 012007, doi:10.1088/1755-1315/14/1/012007, 2011.

de Vernal, A., Hillaire-Marcel, C., Rochon, A., Fréchette, B., Henry, M., Solignac, S., and Bonnet, S.: Dinocyst-based reconstructions of sea ice cover concentration during the Holocene in the Arctic Ocean, the northern North Atlantic Ocean and its adjacent seas, Quaternary Sci. Rev., 79, 111-121, doi:10.1016/j.quascirev.2013.07.006, 2013a.

de Vernal, A., Rochon, A., Fréchette, B., Henry, M., Radi, T., and Solignac, S.: Reconstructing past sea ice cover of the Northern Hemisphere from dinocyst assemblages: status of the approach, Quaternary Sci. Rev., 79, 122-134, doi:10.1016/j.quascirev.2013.06.022, 2013b.

Dubinkina, S., Goosse, H., Sallaz-Damaz, Y., Crespin, E., and Crucifix, M.: Testing a particle filter to reconstruct climate changes over past centuries, Int. J. Bifurcat. Chaos, 21, 3611-3618, doi:10.1142/S0218127411030763, 2011.

Dyke, A. S., Hooper, J., and Savelle, J. M.: A History of Sea Ice in the Canadian Arctic Archipelago Based on Postglacial Remains of the Bowhead Whale (Balaena mysticetus), Arctic, 49, 235255, 1996.

Ebert, E. E. and Curry, J. A.: An intermediate one-dimensional thermodynamic sea ice model for investigating iceatmosphere interactions, J. Geophys. Res., 98, 10085-10109, doi:10.1029/93JC00656, 1993.

England, J. H., Lakeman, T. R., Lemmen, D. S., Bednarski, J. M., Stewart, T. G., and Evans, D. J. A.: A millennial-scale record of Arctic Ocean sea ice variability and the demise of the Ellesmere Island ice shelves, Geophys. Res. Lett., 35, L19502, doi:10.1029/2008GL034470, 2008. 
Farmer, J. R., Cronin, T. M., de Vernal, A., Dwyer, G. S., Keigwin, L. D., and Thunell, R. C.: Western Arctic Ocean temperature variability during the last 8000 years, Geophys. Res. Lett., 38, L24602, doi:10.1029/2011GL049714, 2011.

Flückiger, J., Monnin, E., Stauffer, B., Schwander, J., and Stocker, T. F.: High-resolution Holocene $\mathrm{N}_{2} \mathrm{O}$ ice core record and its relationship with $\mathrm{CH}_{4}$ and $\mathrm{CO}_{2}$, Global Biogeochem. Cy., 16, 101-10-8, 2002.

Francis, J. and Vavrus, S. J.: Evidence linking Arctic amplification to extreme weather in mid-latitudes, Geophys. Res. Lett., 39, L06801, doi:10.1029/2012GL051000, 2012.

Funder, S., Goosse, H., Jepsen, H., Kaas, E., Kjæ r, K. H., Korsgaard, N. J., Larsen, N. K., Linderson, H., Lyså, A., Möller, P., Olsen, J., and Willerslev, E.: A 10,000-year record of Arctic Ocean sea-ice variability-view from the beach, Science, 333, 747-50, doi:10.1126/science.1202760, 2011.

Gent, P. R., Danabasoglu, G., Donner, L. J., Holland, M. M., Hunke, E. C., Jayne, S. R., Lawrence, D. M., Neale, R. B., Rasch, P. J., Vertenstein, M., Worley, P. H., Yang, Z.-L., and Zhang, M.: The Community Climate System Model Version 4, J. Climate, 24, 4973-4991, doi:10.1175/2011JCLI4083.1, 2011.

Goosse, H. and Fichefet, T.: Importance of ice-ocean interactions for the global ocean circulation: A model study, J. Geophys. Res., 104, 23337-23355, 1999.

Goosse, H., Brovkin, V., Fichefet, T., Haarsma, R., Huybrechts, P., Jongma, J., Mouchet, A., Selten, F., Barriat, P.-Y., Campin, J.M., Deleersnijder, E., Driesschaert, E., Goelzer, H., Janssens, I., Loutre, M.-F., Morales Maqueda, M. A., Opsteegh, T., Mathieu, P.-P., Munhoven, G., Pettersson, E. J., Renssen, H., Roche, D. M., Schaeffer, M., Tartinville, B., Timmermann, A., and Weber, S. L.: Description of the Earth system model of intermediate complexity LOVECLIM version 1.2, Geosci. Model Dev., 3, 603-633, doi:10.5194/gmd-3-603-2010, 2010.

Goosse, H., Crespin, E., Dubinkina, S., Loutre, M.-F., Mann, M. E., Renssen, H., Sallaz-Damaz, Y., and Shindell, D.: The role of forcing and internal dynamics in explaining the "Medieval Climate Anomaly", Clim. Dynam., 39, 2847-2866, doi:10.1007/s00382-012-1297-0, 2012.

Goosse, H., Roche, D., Mairesse, A., and Berger, M.: Modelling past sea ice changes, Quaternary Sci. Rev., 79, 191-206, doi:10.1016/j.quascirev.2013.03.011, 2013.

Hanslik, D., Jakobsson, M., Backman, J., Björck, S., Sellén, E., O’Regan, M., Fornaciari, E., and Skog, G.: Quaternary Arctic Ocean sea ice variations and radiocarbon reservoir age corrections, Quaternary Sci. Rev., 29, 3430-3441, doi:10.1016/j.quascirev.2010.06.011, 2010.

Hargreaves, J. C., Annan, J. D., Ohgaito, R., Paul, A., and AbeOuchi, A.: Skill and reliability of climate model ensembles at the Last Glacial Maximum and mid-Holocene, Clim. Past, 9, 811823, doi:10.5194/cp-9-811-2013, 2013.

Holland, M. M. and Bitz, C. M.: Polar amplification of climate change in coupled models, Clim. Dynam., 21, 221-232, doi:10.1007/s00382-003-0332-6, 2003.

Jennings, A. E., Knudsen, K. L., Hald, M., Hansen, C. V., and Andrews, J. T.: A mid-Holocene shift in Arctic sea-ice variability on the East Greenland Shelf, The Holocene, 12, 49-58, doi:10.1191/0959683602hl519rp, 2002.

Kaufman, D., Ager, T., Anderson, N., Andersond, P., Andrews, J., Bartlein, P., Brubaker, L., Coats, L., Cwynar, L., Duvall, M.,
Dyke, A., Edwards, M., Eisner, W., Gajewski, K., Geirsdottir, A., Kaplan, M., Kerwin, M., Lozhkin, A., MacDonald, G., Miller, G., Mock, C., Oswald, W., Otto-Bliesner, B., Porinchu, D., Ruhland, K., Smol, J., Steig, E., and Wolfe, B.: Holocene thermal maximum in the western Arctic $\left(0-180^{\circ} \mathrm{W}\right)$, Quaternary Sci. Rev., 23, 529-560, doi:10.1016/j.quascirev.2003.09.007, 2004.

Lietaer, O., Fichefet, T., and Legat, V.: The effects of resolving the Canadian Arctic Archipelago in a finite element sea ice model, Ocean Model., 24, 140-152, doi:10.1016/j.ocemod.2008.06.002, 2008.

Lohmann, G. and Gerdes, R.: Sea Ice Effects on the Sensitivity of the Thermohaline Circulation*, J. Climate, 11, 2789-2803, doi:10.1175/1520-0442(1998)011<2789:SIEOTS>2.0.CO;2, 1998.

Mairesse, A., Goosse, H., Mathiot, P., Wanner, H., and Dubinkina, S.: Investigating the consistency between proxy-based reconstructions and climate models using data assimilation: a midHolocene case study, Clim. Past, 9, 2741-2757, doi:10.5194/cp9-2741-2013, 2013.

Manabe, S. and Stouffer, R. J.: Sensitivity of a Global Climate Model to an Increase of $\mathrm{CO} 2$ Concentration in the Atmosphere, J. Geophys. Res., 85, 5529-5554, doi:10.1029/JC085iC10p05529, 1980.

Massonnet, F., Fichefet, T., Goosse, H., Bitz, C. M., PhilipponBerthier, G., Holland, M. M., and Barriat, P.-Y.: Constraining projections of summer Arctic sea ice, The Cryosphere, 6, 13831394, doi:10.5194/tc-6-1383-2012, 2012.

Mathiot, P., Goosse, H., Crosta, X., Stenni, B., Braida, M., Renssen, H., Van Meerbeeck, C. J., Masson-Delmotte, V., Mairesse, A., and Dubinkina, S.: Using data assimilation to investigate the causes of Southern Hemisphere high latitude cooling from 10 to 8 ka BP, Clim. Past, 9, 887-901, doi:10.5194/cp-9-887-2013, 2013.

Möller, P., Larsen, N. K., Kjaer, K. H., Funder, S., Schomacker, A., Linge, H., and Fabel, D.: Early to middle Holocene valley glaciations on northernmost Greenland, Quaternary Sci. Rev., 29, 3379-3398, doi:10.1016/j.quascirev.2010.06.044, 2010.

Müller, J., Werner, K., Stein, R., Fahl, K., Moros, M., and Jansen, E.: Holocene cooling culminates in sea ice oscillations in Fram Strait, Quaternary Sci. Rev., 47, 1-14, doi:10.1016/j.quascirev.2012.04.024, 2012.

Notz, D. and Marotzke, J.: Observations reveal external driver for Arctic sea-ice retreat, Geophys. Res. Lett., 39, 1-6, doi:10.1029/2012GL051094, 2012.

Olsen, J., Kjaer, K. H., Funder, S., Larsen, N. K., and Ludikova, A.: High-Arctic climate conditions for the last 7000 years inferred from multi-proxy analysis of the Bliss Lake record, North Greenland, J. Quaternary Sci., 27, 318-327, doi:10.1002/jqs.1548, 2012.

Opsteegh, B. J. D., Haarsma, R. J., Selten, F. M., Kattenberg, A., and Bilt, D.: ECBILT : a dynamic alternative to mixed boundary conditions in ocean models, Tellus A, 50, 348-367, 1998.

Otto-Bliesner, B. L., Joussaume, S., Braconnot, P., Harrison, S. P., and Abe-Ouchi, A.: Modeling and Data Syntheses of Past Climates: Paleoclimate Modelling Intercomparison Project Phase II Workshop, EOS T. Am. Geophys. Un., 90, 2009.

Peltier, W.: Global glacial isostasy and the surface of the ice-ahe Earth: The ICE-5G (VM2) Model and 
GRACE, Annu. Rev. Earth and Pl. Sc., 32, 111-149, doi:10.1146/annurev.earth.32.082503.144359, 2004.

Pollard, D. and DeConto, R. M.: Modelling West Antarctic ice sheet growth and collapse through the past five million years, Nature, 458, 329-32, doi:10.1038/nature07809, 2009.

Polyak, L., Alley, R. B., Andrews, J. T., Brigham-Grette, J., Cronin, T. M., Darby, D. A., Dyke, A. S., Fitzpatrick, J. J., Funder, S., Holland, M., Jennings, A. E., Miller, G. H., O'Regan, M., Savelle, J., Serreze, M., St. John, K., White, J. W., and Wolff, E.: History of sea ice in the Arctic, Quaternary Sci. Rev., 29, 17571778, doi:10.1016/j.quascirev.2010.02.010, 2010.

Renssen, H., Goosse, H., Fichefet, T., Brovkin, V., Driesschaert, E., and Wolk, F.: Simulating the Holocene climate evolution at northern high latitudes using a coupled atmospheresea ice-ocean-vegetation model, Clim. Dynam., 24, 23-43, doi:10.1007/s00382-004-0485-y, 2005.

Renssen, H., Seppä, H., Heiri, O., Roche, D. M., Goosse, H., and Fichefet, T.: The spatial and temporal complexity of the Holocene thermal maximum, Nat. Geosci., 2, 411-414, doi:10.1038/ngeo513, 2009.

Rotstayn, L. D., Collier, M. A., Dix, M. R., Feng, Y., Gordon, H. B., O'Farrell, S. P., Smith, I. N., and Syktus, J.: Improved simulation of Australian climate and ENSO-related rainfall variability in a global climate model with an interactive aerosol treatment, Int. J. Climatol., 30, 1067-1088, doi:10.1002/joc.1952, 2009.

Screen, J. A. and Simmonds, I.: The central role of diminishing sea ice in recent Arctic temperature amplification, Nature, 464, 1334-7, doi:10.1038/nature09051, 2010.

Serreze, M. C., Holland, M. M., and Stroeve, J.: Perspectives on the Arctic's shrinking sea-ice cover, Science, 315, 1533-1536, doi:10.1126/science.1139426, 2007.

Serreze, M. C., Barrett, A. P., Stroeve, J. C., Kindig, D. N., and Holland, M. M.: The emergence of surface-based Arctic amplification, The Cryosphere, 3, 11-19, doi:10.5194/tc-3-11-2009, 2009.

Stevens, B., Giorgetta, M., Esch, M., Mauritsen, T., Crueger, T., Rast, S., Salzmann, M., Schmidt, H., Bader, J., Block, K., Brokopf, R., Fast, I., Kinne, S., Kornblueh, L., Lohmann, U., Pincus, R., Reichler, T., and Roeckner, E.: The atmospheric component of the MPI-M earth system model: ECHAM6, Journal of Advances in Modeling Earth Systems, 5, 1-27, doi:10.1002/jame.20015, 2013.

Stroeve, J. C., Serreze, M. C., Holland, M. M., Kay, J. E., Malanik, J., and Barrett, A. P.: The Arctic's rapidly shrinking sea ice cover: a research synthesis, Climatic Change, 110, 1005-1027, doi:10.1007/s10584-011-0101-1, 2011.

Stroeve, J. C., Kattsov, V., Barrett, A., Serreze, M., Pavlova, T., Holland, M., and Meier, W. N.: Trends in Arctic sea ice extent from CMIP5, CMIP3 and observations, Geophys. Res. Lett., 39, 1-7, doi:10.1029/2012GL052676, 2012.

Sundqvist, H. S., Zhang, Q., Moberg, A., Holmgren, K., Körnich, H., Nilsson, J., and Brattström, G.: Climate change between the mid and late Holocene in northern high latitudes - Part 1: Survey of temperature and precipitation proxy data, Clim. Past, 6, 591608, doi:10.5194/cp-6-591-2010, 2010
Taylor, K. E., Stouffer, R. J., and Meehl, G. A.: An Overview of CMIP5 and the Experiment Design, B. Am. Meteorol. Soc., 93, 485-498, doi:10.1175/BAMS-D-11-00094.1, 2012.

van Leeuwen, P. J.: Particle Filtering in Geophysical Systems, Mon. Weather Rev., 137, 4089-4114, doi:10.1175/2009MWR2835.1, 2009.

Vare, L. L., Massé, G., Gregory, T. R., Smart, C. W., and Belt, S. T.: Sea ice variations in the central Canadian Arctic Archipelago during the Holocene, Quaternary Sci. Rev., 28, 1354-1366, doi:10.1016/j.quascirev.2009.01.013, 2009.

Voldoire, A., Sanchez-Gomez, E., Salas y Mélia, D., Decharme, B. Cassou, C., Sénési, S., Valcke, S., Beau, I., Alias, A., Chevallier, M., Déqué, M., Deshayes, J., Douville, H., Fernandez, E., Madec, G., Maisonnave, E., Moine, M.-P., Planton, S., SaintMartin, D., Szopa, S., Tyteca, S., Alkama, R., Belamari, S., Braun, A., Coquart, L., and Chauvin, F.: The CNRM-CM5.1 global climate model: description and basic evaluation, Clim. Dynam., 40, 2091-2121, doi:10.1007/s00382-011-1259-y, 2012.

Wanner, H., Beer, J., Bütikofer, J., Crowley, T. J., Cubasch, U., Flückiger, J., Goosse, H., Grosjean, M., Joos, F., Kaplan, J. O., Küttel, M., Müller, S. A., Prentice, I. C., Solomina, O., Stocker, T. F., Tarasov, P., Wagner, M., and Widmann, M.: Mid- to Late Holocene climate change: an overview, Quaternary Sci. Rev., 27, 1791-1828, doi:10.1016/j.quascirev.2008.06.013, 2008.

Watanabe, S., Hajima, T., Sudo, K., Nagashima, T., Takemura, T., Okajima, H., Nozawa, T., Kawase, H., Abe, M., Yokohata, T., Ise, T., Sato, H., Kato, E., Takata, K., Emori, S., and Kawamiya, M.: MIROC-ESM 2010: model description and basic results of CMIP5-20c3m experiments, Geosci. Model Dev., 4, 845-872, doi:10.5194/gmd-4-845-2011, 2011.

Wu, T., Song, L., Li, W., Wang, Z., Zhang, H., Xin, X., Zhang, Y., Zhang, L., Li, J., Wu, F., Liu, Y., Zhang, F., Shi, X., Chu, M., Zhang, J., Fang, Y., Wang, F., Lu, Y., Liu, X., Wei, M., Liu, Q., Zhou, W., Dong, M., Zhao, Q., Ji, J., Li, L., and Zhou, M.: An overview of BCC climate system model development and application for climate change studies, Journal of Meteorological Research, 28, 34-56, doi:10.1007/s13351-014-3041-7, 2014

Yukimoto, S., Adachi, Y., Hosaka, M., Sakami, T., Yoshimura, H., Hirabara, M., Tanaka, T. Y., Shindo, E., Tsujino, H., Deushi, M., Mizuta, R., Yabu, S., Obata, A., Nakano, H., Koshiro, T., Ose, T., and Kitoh, A.: A New Global Climate Model of the Meteorological Research Institute: MRI-CGCM3 - Model Description and Basic Performance -, J. Meteorol. Soc. Jpn., 90A, 23-64, doi:10.2151/jmsj.2012-A02, 2012.

Zhang, J., Woodgate, R., and Moritz, R.: Sea Ice Response to Atmospheric and Oceanic Forcing in the Bering Sea, J. Phys. Oceanogr., 40, 1729-1747, doi:10.1175/2010JPO4323.1, 2010. 